San Jose State University

SJSU ScholarWorks

Master's Theses

Master's Theses and Graduate Research

Spring 2014

\title{
Computational Fluid Dynamics Modeling of Two-Dimensional and Three-Dimensional Segmented Flow in Microfluidic Chips
}

Katrina Jolene Donovan

San Jose State University

Follow this and additional works at: https://scholarworks.sjsu.edu/etd_theses

\section{Recommended Citation}

Donovan, Katrina Jolene, "Computational Fluid Dynamics Modeling of Two-Dimensional and ThreeDimensional Segmented Flow in Microfluidic Chips" (2014). Master's Theses. 4412.

DOI: https://doi.org/10.31979/etd.3tzd-y6xm

https://scholarworks.sjsu.edu/etd_theses/4412

This Thesis is brought to you for free and open access by the Master's Theses and Graduate Research at SJSU ScholarWorks. It has been accepted for inclusion in Master's Theses by an authorized administrator of SJSU ScholarWorks. For more information, please contact scholarworks@sjsu.edu. 


\title{
COMPUTATIONAL FLUID DYNAMICS MODELING
}

OF TWO-DIMENSIONAL AND THREE-DIMENSIONAL SEGMENTED

\section{FLOW IN MICROFLUIDIC CHIPS}

\author{
A Thesis \\ Presented to \\ The Faculty of the Department of Chemistry \\ San José State University \\ In Partial Fulfillment \\ of the Requirement for the Degree \\ Master of Science
}

By

Katrina J. Donovan

May 2014 
(C) 2014

Katrina J. Donovan

ALL RIGHTS RESERVED 


\section{COMPUTATIONAL FLUID DYNAMICS MODELING}

OF TWO-DIMENSIONAL AND THREE-DIMENSIONAL SEGMENTED

FLOW IN MICROFLUIDIC CHIPS

by

Katrina J. Donovan

APPROVED FOR THE DEPARTMENT OF CHEMISTRY

SAN JOSÉ STATE UNIVERSITY

May 2014

Dr. Bradley Stone Department of Chemistry

Dr. Andrew deMello Department of Biomedical Engineering, ETH, Zurich, Switzerland

Dr. Joseph Pesek Department of Chemistry

Dr. Brooke Lustig Department of Chemistry

Dr. Gregory Young Department of Biomedical, Chemical, and Materials Engineering 


\begin{abstract}
COMPUTATIONAL FLUID DYNAMICS MODELING

OF TWO-DIMENSIONAL AND THREE-DIMENSIONAL SEGMENTED

FLOW IN MICROFLUIDIC CHIPS
\end{abstract}

By Katrina J. Donovan

Microfluidics is a rapidly growing topic of interest for scientists, engineers, and medical researchers. The micrometer length scale constrains flow to a laminar behavior, allowing for a more predictable system. High-throughput experimentationis possible with laminar multiphase flow, specifically microdroplets. Manipulating microdroplets by generating, splitting, separating, and fusing provides a versatile environment for analysis in a variety of biological and chemical systems.

The process of design, fabrication, and testing of microfluidic systems is an iterative and tedious procedure. The purpose of this research was to utilize computational fluid dynamics software to expedite the fabrication and design process by simulating time-dependent data as droplets flowthrough a channel. The two-dimensional segmented flowinvestigated the effect of droplet generation by inspecting three different nozzle widths combined with four different post nozzle designs. Droplets were successfully generated in all nozzle widths and all post nozzle geometries, but certain nozzle and post nozzle geometries were found to be a more efficient combination. The three-dimensional project analyzes droplet generation and merging in a pillar induced merging chamber. Multiple droplets successfully merged in the three-dimensional analysis. 


\section{ACKNOWLEDGEMENTS}

Financial and computational support for this project was provided through two sources. The Intel Grant 32553 provided financial support for purchasing the computer cluster. The principal investigators for this work were Dr. Brooke Lustig and Dr. Patrick Fleming. The second source was the CSUPERB Grant 2009 which provided financial support to purchase an operating system for the cluster, COMSOL Multiphysics ${ }^{\circledR}$, and provide a stipend. The principal investigators for this work are Dr. Bradley Stone and Dr. Andrew deMello.

I would like to thank my advisor, Dr. Stone, for this project. This project provided me the opportunity to explore a multidisciplinary field outside the Chemistry Department. I am thankful for his encouragement, time, and support over these past years as I have strived to complete my degree. I am especially grateful for the patience he has while I raised a family, worked, and completed my thesis.

I would like to thank the members of my committee, Dr. Joseph Pesek, Dr. Gregory Young, Dr. Brooke Lustig, and Dr. deMello. Dr. Pesek has always been very responsive to all queries I have had along this journey and it was a pleasure working with him on this project. Dr. Young was invaluable to this project as it was under his tutelage that I began to understand the physical phenomena occurring within my research. Dr. Lustig's knowledge of technology was instrumental in setting up the cluster and maintaining the operating state of the cluster.

I would like to thank Dr. deMello for providing me with the opportunity to be a part of this work. This project originated in Dr. deMello's group, and the experimental 
side of this work was performed by his group. I would like to thank these members of his group: Dr. Xize Niu, Dr. Xavier Casadevalli Solvas, and Dr. Shelly Gulati.

I want to thank my extended family for all their support. Sidney and Sharon Dimond have been very supportive by watching my sons' for the past couple years as I have worked towards completing my degree. I want to thank my husband's mother, Jody Sibal, and grandmother, Paula Walker as they have done a wonderful job of helping babysit my children.

I would like to thank my parents, Marjorie and Jerry Joe Donovan, for all their encouragement and confidence over the years. I doubt they will know how much I value their support. I would like to thank all my siblings: Debbie, Annette, TJ, Billie, Jennie, Jeremiah, and Michaela. I would especially like to thank Jennie as she has always been willing to be a fresh pair of eyes reviewing my papers.

Finally, I would like to thank my immediate family. Dane and Kai, you have been a constant source of happiness through my time at San Jose State University. Thank you for bringing a smile to my face and joy to my heart. I would like to thank my husband, Travis Walker. He has been my rock throughout this process by assisting me through many of the challenging courses and providing emotional support. I am thankful that he has always been in my corner. 


\section{TABLE OF CONTENTS}

1 Introduction 1

1.1 Motivation

1.2 Microfluidics 1

$\begin{array}{ll}1.3 \text { Microdroplets } & 4\end{array}$

$\begin{array}{ll}\text { 1.4 Miniaturization } & 7\end{array}$

$\begin{array}{ll}1.5 \text { Reynolds Number } & 9\end{array}$

1.6 Laminar Flow vs. Turbulent Flow $\quad 9$

1.7 Pressure Driven Flow vs. Electroosmotic Flow 11

$\begin{array}{ll}1.8 \text { Navier-Stokes Equation and High Fluidic Resistance } & 13\end{array}$

2 COMSOL Multiphysics ${ }^{\circledR} \quad 15$

$\begin{array}{ll}2.1 \text { Background } & 15\end{array}$

$\begin{array}{ll}\text { 2.2 Single Phase and Multiphase Flow } & 16\end{array}$

$\begin{array}{ll}2.3 \text { Level Set Method } & 18\end{array}$

$\begin{array}{ll}2.4 \text { Finite Element Modeling } & 19\end{array}$

3 Experimental Procedures 21

3.1 Three-Dimensional T-junction Design $\quad 21$

3.2 Three-Dimensional Pillar Induced Merging Chamber Design 22

3.3 Fluidic Properties of Three-Dimensional Microdroplets 23

3.4 Two-Dimensional Nozzle Geometries 23

3.5 Two-Dimensional Flow Focusing Junction Design 24

3.6 Two-Dimensional Nozzle 24 
3.7 Two-Dimensional Post-Nozzle Geometry

3.8 Two-Dimensional Nozzle Fluid Properties

4 Two-Dimensional CFD Analysis of Nozzles

4.1 90 Degree Post Nozzle Geometry

4.2 Straight Post Nozzle Geometry

4.3 Abrupt Post Nozzle Geometry

4.4 Gradual Post Nozzle Geometry 35

4.5 Computational Validation 36

$\begin{array}{ll}\text { 4.6 Summary } & 37\end{array}$

5 Three-Dimensional Segmented Flow 39

5.1 T-junction Verification 39

5.2 Merging Chamber $\quad 41$

6 Conclusions 45

$\begin{array}{ll}\text { Bibliography } & 47\end{array}$ 


\section{LIST OF TABLES}

Table I: Fluid Volume in Relation to Micron Dimension

Table II: COMSOL Multiphysics ${ }^{\circledR}$ available platforms with emphasis on the fluidic platform

Table III: Fluidic Properties of the Three-Dimensional Microdroplets

Table IV: Two-Dimensional Nozzle Fluid Properties

Table V:Simulation Lists of 90 Degree Post Nozzle Geometry

Table VI:Simulation Lists of Straight Post Nozzle Geometry

Table VII: Simulation Lists of Abrupt Post Nozzle Geometry

Table VIII: Simulation Lists of Gradual Post Nozzle Geometry

Table IX: Summary of Droplet Formation from all Simulations 


\section{LIST OF FIGURES}

Figure 1: Schematic of a symmetric bifurcating droplet separator.

Figure 2: Schematic of an asymmetric droplet separator.

Figure 3: Schematics of two different microchannel fluid traps.

Figure 4: A-Schematic of laminar flow in a channel.

Figure 5: A-Schematic of pressure driven flow within a channel.

Figure 6: Image of the model builder, root, and graphics section of COMSOL Multiphysics ${ }^{\circledR}$ software package.

Figure 7: Schematic of a droplet flowing through a channel.

Figure 8: Image from COMSOL Multiphysics ${ }^{\circledR}$ of a T-junction with mesh elements applied to the geometry.

Figure 9:Image from COMSOL Multiphysics ${ }^{\circledR}$ of a pillar induced merging chamber with mesh elements applied to the geometry.

Figure 10: Image from COMSOL Multiphysics ${ }^{\circledR}$ of a flow focusing junction.

Figure 11: Images from COMSOL Multiphysics ${ }^{\circledR}$ of nozzles with throat widths of A-23 $\mu \mathrm{m}, \mathrm{B}-45 \mu \mathrm{m}$, and C-100 $\mu \mathrm{m}$. 
Figure 12: Image from COMSOL Multiphysics ${ }^{\circledR}$ of a straight channel post nozzle geometry.

Figure 13: Image from COMSOL Multiphysics ${ }^{\circledR}$ of an abrupt post nozzle geometry.

Figure 14: Image from COMSOL Multiphysics ${ }^{\circledR}$ of a 90 degree post nozzle geometry.

Figure 15: Image from COMSOL Multiphysics ${ }^{\circledR}$ of a gradual post nozzle geometry.

Figure 16: Images from COMSOL Multiphysics ${ }^{\circledR}$ of a 90 degree post nozzle geometry with throat widths of A-45 $\mu \mathrm{m}, \mathrm{B}-23 \mu \mathrm{m}$, and C-100 $\mu \mathrm{m}$.

Figure 17:Image from COMSOL Multiphysics ${ }^{\circledR}$ of streamlines from a 90 degreepost nozzle geometry with a nozzle width of $23 \mu \mathrm{m}$.

Figure 18: Images from COMSOL Multiphysics ${ }^{\circledR}$ of a $100 \mu \mathrm{m}$ nozzle with a straight channel post nozzle geometry.

Figure 19: Image from COMSOL Multiphysics ${ }^{\circledR}$ of a flow focusing junction.

Figure 20: Images from the study performed by van Steijn, et al.

Figure 21: Image from COMSOL Multiphysics ${ }^{\circledR}$ of a pillar induced merging chamber. 
Figure 22: Images from COMSOL Multiphysics ${ }^{\circledR}$ of droplets entering the merging chamber. 


\section{Chapter 1: Introduction}

\subsection{Motivation}

Microfluidics is a growing field of interest for scientists, engineers, and medical researchers. The small length scale in microfluidics offers researchers a controllable platform with easy portability, minimal waste, and superior analytic performance. Many pharmaceutical, biotechnology, and environmental health industries have begun extensive research into microfluidics.

In this work, I focus on utilizing computational fluid dynamics software for optimizing and predicting outcomes for experiments. Specifically, I focus on the functionality of microdroplet generation and fusion. The ability to manipulate droplets opens new avenues for drug discovery, material synthesis, medical diagnostics, and medical treatment. ${ }^{1}$

Microfluidic device fabrication and testing is a time-consuming and iterative procedure. By simulating droplet merging through computational fluid dynamics, quick design and optimization results in less material waste and elimination of the design, fabrication, and testing phases.

\subsection{Microfluidics}

Microfluidics is a subset of fluid mechanics that integrates physics and engineering on a micrometer length scale. The versatile nature of microfluidics provides a robust environment and controllable platform that chemists, biologists, and medical researchers utilize for various analyses such as DNA sequence analysis, DNA 
amplification, polymerase chain reaction, capillary electrophoresis, chromatography, mass spectrometry, and chemical synthesis. ${ }^{1,2}$

By utilizing the micron length scale, fluid flow is constrained to a laminar behavior. On a small length scale, viscous forces dominate over inertial forces. The lack of inertial forces allows for a more predictable system with high-throughput experimentation capabilities and the ability to execute millions of genetic, biological, chemical, and pharmacological tests rapidly. For microfluidic systems, flow rates are in the lower microliter per minuterange, channel widths extend from 5-200 $\mu \mathrm{m}$, and fluid volumes span microliters to picoliters. ${ }^{2}$

To provide a tangible basis for comparison, a human hair has an approximate volume of $1 \mathrm{~nL}$ and a red blood cell is approximately $1 \mathrm{pL}^{2}$ Table I provides approximate reference points, thereby enhancing an understanding of the length scales that microfluidic devices operate.

Table I: Fluid Volume in Relation to Micron Dimension

\begin{tabular}{ccc}
\hline Volume of a Cube & Reference & Size $(\mu \mathrm{m})$ \\
\hline $1 \mathrm{pL}$ & Red Blood Cell Diameter & 10 \\
$1 \mathrm{~nL}$ & Diameter of a Strand of Hair & 100 \\
$1 \mu \mathrm{L}$ & Head of a pin & 1,000 \\
$1 \mathrm{~mL}$ & Size of a single sugar cube & 10,000 \\
\hline
\end{tabular}

The complexity of microfluidic devices is dependent on the function of the system. One example of a simple but commonly used microfluidic device is a fluidic mixer. An example of a more complex microfluidic device is a system utilizing pneumatic pumps for mixing fluids. ${ }^{2}$ Another example is a system requiring an electric potential across the channel to induce fluid flow. ${ }^{2}$ Understanding the behavior of fluids 
and learning how to control and manipulate small volumes of fluid allow for exceptional performance in sensitivity, speed, and spatial resolution.

The focus of this study wasto analyze systems that utilize geometric designs to control fluids, using a passive method, rather than external accessories such as pneumatic pumps and electric potential. Some common applications of microfluidics are lab-on-achip technology, DNA chips, microthermal, and micropropulsion technologies. An inkjet printer is one common device that resides in most homes today and is the first microfluidic device engineered. ${ }^{3}$

Consumers are looking for miniature, time-conscious, and cost-effective equipment. Microfluidic devices utilizing high-throughput experimentation provides this platform to consumers with additional benefits. Microfluidic devices perform more time efficiently than a lab. Simultaneously, they are more cost effective as less waste and smaller quantities of materials are required and they are capable of utilizing all aspects of a human-scale lab. Also, shorter time is required to view results due to high surface-tovolume ratios occurring from shorter heat and mass transfer times. ${ }^{4}$

For these reasons, biotechnology companies, environmental health industries, and pharmaceutical companies have become interested in microfluidic systems. ${ }^{4}$ The biotechnology industry is interested in protein analysis and gene expression. Biotechnology firms screen proteins against another protein for binding or reactivity and investigate gene expression by utilizing polymerase chain reaction, PCR, primers, as well as perform genome-wide gene silencing studies on siRNA, silencing RNA. ${ }^{5}$ Tests for toxicity by evaluating organic compounds against living cells are performed by a number 
of environmental health companies. Pharmaceutical companies test drug compounds and natural products against a protein or cells of interest. ${ }^{5}$

\subsection{Microdroplets}

As previously mentioned, high-throughput experimentation for microdroplets is possible with laminar segmented multiphase flow. Utilizing flow instabilities between immiscible fluids, suspended microdroplets are generated. Microdroplets act as independent reactors in chemical and biological systems. ${ }^{6}$

The compartmentalization of reactions to microdroplets provides an entirely new approach to experimental science. Microdroplet systems are composed of a two-phased flow, or segmented flow. Commonly, the droplets are either oil or water. Oil-in-water droplets are oil droplets suspended in water. In this scenario, the oil is the dispersed phase and the water is the aqueous carrier phase. Water-in-oil droplets are water droplets suspended in the oil carrier phase. ${ }^{2}$ The water droplets are the dispersed aqueous phase.

Assuming water is the segmented droplet phase and oil is the carrier, oil provides a physical barrier between the droplets and the walls. Depending on the nature of the experiment, the droplet phase, most commonly aqueous, may contain some specific item of interest: RNA, DNA, and enzymes. ${ }^{6}$ Some specific uses for microdroplets are enzymatic assays, protein crystallization, nanomaterial synthesis, high-throughput binding assays, medical diagnostics, polymerase chain reactions, and many other processes. ${ }^{5,6}$

The research discussed in this thesis focuses on microdroplet manipulation, specifically generation and fusion. Droplet generation results from the shearing of one 
fluid phase with another. For this shearing to occur the fluids must be immiscible. The commonly used pairing in microfluidic devicesis oil and water. A flow focusing junctionor a T-junctionare common geometries utilized in droplet generation. ${ }^{1}$ A flow focusing junction is comprised of three channels merging into one anda $\mathrm{T}$-junction is the merging of two channels into one.

Droplets can also be split and separated.Droplet splitting occurs by dividing a parent droplet into two daughter droplets. Commonly, droplet splitting is executed by a single parent channel bifurcating into two daughter channels. The droplet will impact the bifurcation and divide into two separate droplets, the daughter droplets. ${ }^{7}$ If the geometry of the bifurcation is symmetric, the daughter droplets will be divided equally. For this process to efficiently split a droplet, the droplet should have a diameter that is equivalent to the width of the microchannel.

Various geometric designs have been used to split or sort droplets. An example of droplet sorting system similar to a microfluidic system utilized by Mazutisa and Griffiths can be seen in Figure 1. They took advantage of a hydrodynamic effect that caused smaller droplets to flow near the wall of the channel rather than in the center of the channel. ${ }^{7}$ This phenomenon allowed the group to create two smaller branches for the smaller droplets to separate from the larger droplets. In channels with no applied current, fluid flows fastest at the center of the channel because the fluid is experiencing less resistance relative to the fluid near the wall. 


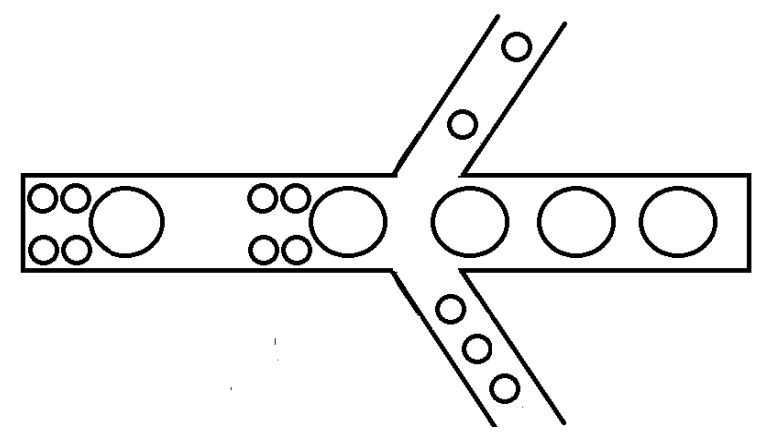

Figure 1: Schematic of a symmetric bifurcating droplet separator.This droplet separator utilizes hydrodynamic effects that result in small droplets near the channel walls. Daughter channels are then used to remove the smaller droplets from the main channel.

Tan, Ho, and Lee designed an alternative passive droplet sorting system, similar to the image seen in Figure $2{ }^{8}$ The daughter channels from the bifurcation junction exert a shear force on the droplet resulting in a droplet moving in the direction of higher flow. The shear force experienced by a droplet is dependent on the ratio of shear rates. ${ }^{8}$ The shear rate is generated by the daughter flows and the ratio of the area of the projected daughter channel. ${ }^{8}$ Droplets are sorted according to size.

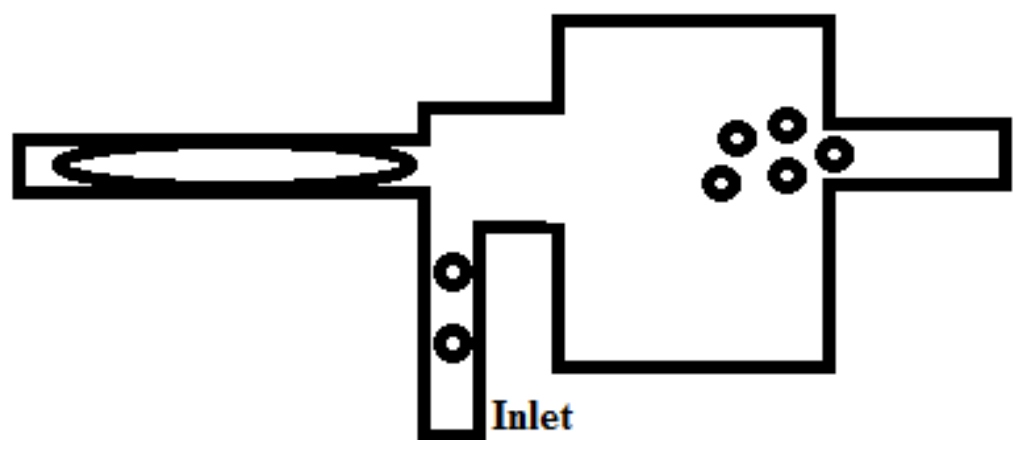

Figure 2: Schematic of an asymmetric droplet separator.Two outlets are used to separate large droplets from small droplets. The daughter channels from the bifurcation junction exert a shear force on the droplet resulting in a droplet moving in the direction of higher flow.

Droplet fusing and merging is an important area of interest for researchers because it provides the ability to encapsulate a single target sample with another material. ${ }^{5}$ Encapsulation is commonly used for cell transportation, nanosynthesis, or 
hydrogel-bead production. Droplet merging allows systems to mix two or more droplets containing separate material in a setting that allows for a precise combination of reagents. Adding reagents can affect the reaction's thermodynamics, providing either an inhibitor or initiator. ${ }^{5}$

This research focuses on passive droplet merging techniques, specifically pillar induced droplet merging. Two examples of passive droplet merging are illustrated in Figure 3. Passive droplet merging utilizes fluidic resistance elements such as pillars, expansion chambers, two chambers merging to one, and large channel diminishing intoa narrow channel. ${ }^{9}$ The fluidic resistance element slows or traps droplets, thereby causing droplet fusion. Figure 3A represents an expansion chamber which causes droplets to slow as they enter the expansion chamber. ${ }^{9}$ Figure $3 \mathrm{~B}$ is a schematic of a pillar arraycombined with an expansion chamber to slow droplets. ${ }^{9}$ Both images are examples of passive droplet merging systems.
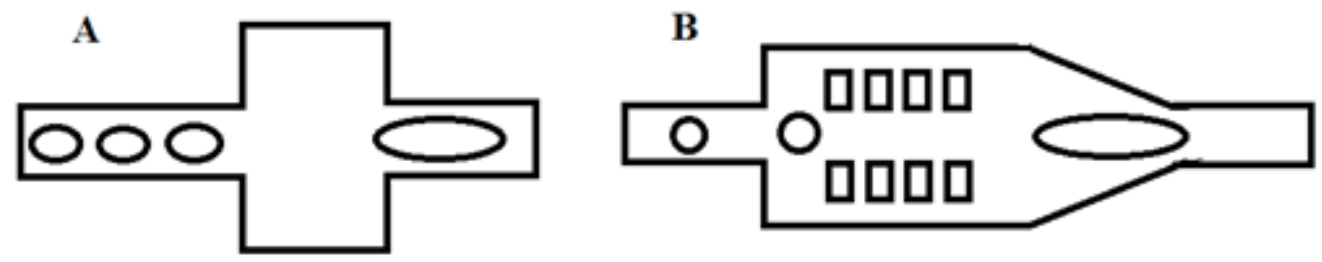

Figure 3: Schematics of two different microchannel fluid traps. A-Schematic of an expansionchamber with thesmaller ovals representing droplets flowing through the channel and the larger oval represents a large droplet composed of several merged droplets. B-Schematic of an expansion chamber combined with pillar arrays. The rectangles are the pillar arrays, the circles are droplets, and the large oval droplet represents multiple droplets that have merged.

\subsection{Miniaturization}

Improved sensitivity, speed, and spatial resolution are positive attributes of miniaturization that appeal to a diverse group of professionals. ${ }^{2}$ This subsection focuses 
on scaling laws associated with miniaturization and the negative side effects of miniaturization.

A fundamental concept for scaling laws is the surface-to-volume ratio. In microfluidics, the surface to volume ratio is very high, allowing for rapid heat and mass transfer. $^{2}$ At high surface-to-volume ratios, parameters such as inertia are negligible because they are based on mass and volume. ${ }^{2}$ Surface charge, wetting behavior, surface tension, diffusion, and viscosity play a vital role in the microscopic environment. ${ }^{2}$

There are a couple of negative aspects observed in the miniaturization of microfluidic systems. Reducing the size of the microplates can cause the following problems such as evaporation, surface adsorption, robot imprecision, and liquid handling. ${ }^{4}$ However, microfluidic channels do not suffer from the previously listed problems because they are enclosed systems that require minimal liquid handling or robotic assistance. Therefore, researchers have the ability to continue to decrease the size of microdroplet system with controllable negative aspects. ${ }^{10}$ The robust nature of microdroplet systems provides the ability to meet the growing industrial demand for ultra high-throughput assays. ${ }^{10}$

Miniaturization has become of increasing interests to the aeronautics and space community. Microfluidic devices cater to the limited room and power available in a space craft. ${ }^{3}$ An operating microfabricated electrophoresis system consumes less than one watt of power, yet still provides highly analytical, timely, andefficient chemical separations for a variety of molecular species. ${ }^{3}$ 


\subsection{Reynolds Number}

The Reynolds number, Re, is a dimensionless number that is a ratio of inertial forces to viscous forces and can be viewedin Equation 1. The denominator is composed of the viscous forces, specifically the dynamic viscosity, $\mu$. The numerator contains the variables that compose of the inertial forces: density $(\rho)$; mean velocity $(U)$; and length the fluid has traveled (L). ${ }^{2}$

$$
R e=\frac{\rho U L}{\mu}=\frac{\text { inertialforces }}{\text { viscousforces }}
$$

A Reynolds number is used to describe three separate flow conditions: turbulent, laminar, and transitional. ${ }^{2}$ Research conducted in this thesis deals entirely with laminar flow. In the microfluidic environment, fluid flow has a Reynolds number that is less than one. ${ }^{2}$ When a Reynolds number is less than one, slow or "creeping" flow occurs. This type of flow is known as Stokes flow. In Stokes flow, the advective inertial forces are minimal relative to viscous forces. ${ }^{2}$ A couple characteristics of Stokes flow are low velocities, small flow length scales, and large viscosities.

\subsection{Laminar Flow vs. Turbulent Flow}

A simple definition of laminar is layered. In laminar flow, streamlines occur in parallel layers due to the lack of perturbation between layers at low velocities and in small pipes. Laminar flow does not have cross current flows or eddies. Therefore, the system has a highly reproducible and controllable environment. ${ }^{2}$ Laminar flow in microfluidic channels has a parabolic profile resulting from the friction between the fluid and wall. The wall reduces the velocity of the fluid near the wall. The fluid in the center 
of the channel is moving the quickest, resulting in the parabolic profile. Shear stress in laminar flow is independent of density and is almost only dependent upon the viscosity. ${ }^{2}$ Laminar flow is characterized by a Reynolds number less than $2,300 .^{2}$

The reproducibility of laminar flow allows scientists to predict particle, droplet, and fluid trajectory. ${ }^{10}$ Laminar flow also allows for diffusive separation of particles. The ability to predict and control fluid movement is extremely important for analysis in chemical and biological systems. ${ }^{11}$

Turbulent flow is identified as stochastic flow, meaning that the turbulent flow has some predictable actions along with a random variable. Due to the random variable, turbulent flow is a much less desirable flow to choose when trying to predict flow for droplets or particle tracking. ${ }^{2}$ However, it is a highly desirable mechanism when mixing two fluids.A schematic of laminar and turbulent flow can be seen below in Figure 4.

A
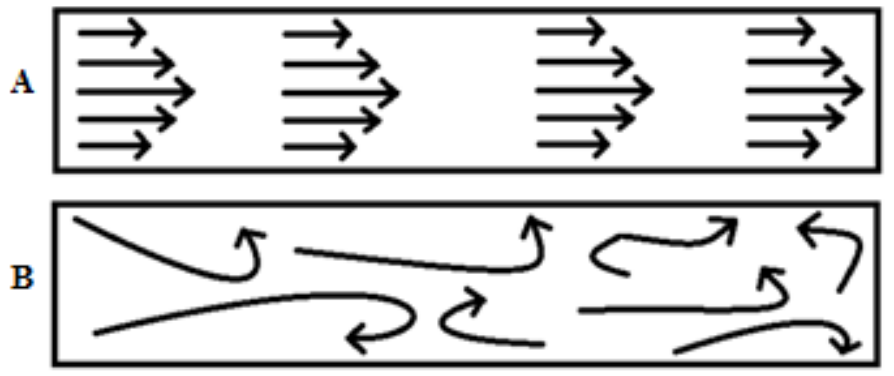

Figure 4: A-Schematic of laminar flow in a channel. The arrows represent the velocity and trajectory of the fluid. For laminar flow, the fluid flows fastest at the center and the fluid has a layered effect. Therefore, the arrows are longest at the center and the arrows are stacked on top of each other representing a predictable layering effect. B-Schematic of turbulent flow in a channel. The arrows represent the trajectory of the fluid. The trajectory is difficult to predict in turbulent flow.

Eddies, cross current flow, and vortices are phenomena observed in turbulent flow. There is limited predictability within a system consisting of turbulent flow. The 
Reynolds number for turbulent flow is found to be greater than $4,000 .^{12}$ The shear stress for turbulent flow is a function of the density of the fluid.

Fluid flow is not binary. There is significant gray area; this is the transitional flow region. Transitional flow has both turbulent and laminar behavior. The transitional region is located between a Reynolds number of 2,300 and 4,000. ${ }^{2}$

\subsection{Pressure Driven Flow vs. Electroosmotic Flow}

There are two common methods to move fluid through microchannels: pressure driven flow and Electroosmotic flow. In pressure driven flow, fluid is pumped through the channels by a positive displacement pump. ${ }^{2}$ A fundamental principle of fluid mechanics in regards to pressure driven flow, is the no-slip boundary condition. According to the no-slip boundary condition, the fluid velocity at the walls is equal to

zero, this condition results in a parabolic profile. ${ }^{13}$ An image of pressure driven flow can be seen in Figure $5 \mathrm{~A}$.

The parabolic velocity is very useful and important for the distribution of molecules. Pressure driven flow is a reproducible and somewhat inexpensive method for actuating flow. ${ }^{14}$ Given the recent improvements in micropumps, pressure driven flow has the ability to be further miniaturized. 


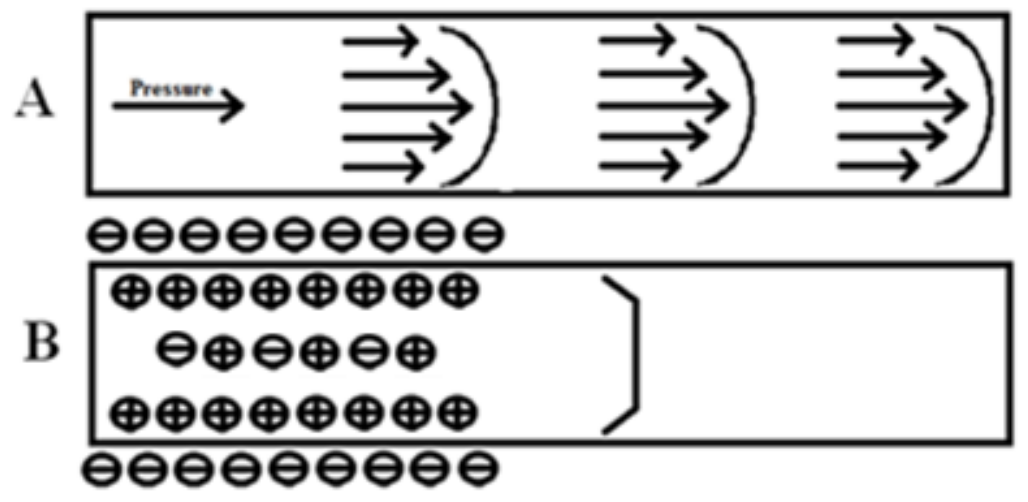

Figure 5: A-Schematic of pressure driven flow within a channel. The arrows represent the velocity and the trajectory of the fluid. The half circle infront (or to the right) of the arrows illustrates the parabolic profile of fluid flow. The arrow with pressure above it represents a pressure drive pump which provides the driving force for the fluid. B-Schematic of Electroosmotic flow within a channel.The negative signs on the outside of the channel represent the applied current, and the positive signs and negative signs within the channel are charged ions.

Electroosmotic flow is the motion of liquid through a microchannel that occurs as a result of an electric potential across the channel to induce fluid flow. ${ }^{2}$ As can be seen in Figure 5B, the potential essentially pulls fluid through the channel with a velocity profile that is almost planar. There is a small lag near the wall that results from the electric double layer.

Electroosmotic flow is more efficient in microchannels relative to macrochannels due to the high surface-to-volume ratio at smaller length scales. Electroosmotic flow is very useful for chemical separations as it can occur in unfiltered water and buffered solutions. Simultaneously, this system can provide a high performance method for fluid separation that can be controlled without valves and minimal dispersive effect; although the technique itself is very challenging. ${ }^{2}$ One of the most common types of Electroosmotic flow is capillary electrophoresis. 


\subsection{Navier-Stokes Equation and High Fluidic Resistance}

The major contributing factor to the previously mentioned excellent performance of microfluidic devices is the small size scale of the device. ${ }^{2}$ With a smaller length scale, viscous forces dominate over inertial forces because of the decreasing size of the device's body forces, which are scaled cubically. ${ }^{2}$ As a result, when analyzing pressure driven flow, a higher fluidic resistance is observed due to the decreasing length scale.

In Equation 2, the Navier-Stokes equation is given for incompressible flow of a Newtonian liquid through a channel under a pressure gradient, $\nabla \mathrm{p}$. The Navier-Stokes equation balances the inertial component of the fluid, $\rho\left[\frac{\delta \vec{u}}{\delta t}+\vec{u} * \nabla \vec{u}\right]$, against the pressure and shear stress, $\mu \nabla^{2} \overrightarrow{\mathrm{u}}^{2}$

$$
\rho\left[\frac{\delta \vec{u}}{\delta t}+\vec{u} * \nabla \vec{u}\right]=-\nabla p+\mu \nabla^{2} \overrightarrow{\mathrm{u}}
$$

The Navier-Stokes equation can be adjusted to more accurately model microfluidic systems. ${ }^{2}$ One adjustment is eliminating the convective term because it is negligible when fluid flow correlates to a Reynolds numbers lower than one. Another assumption that can be made is to assume steady state inlet conditions, therefore fluid velocity is not a function of time, eliminating the time dependency term. By applying these two simplifications, the equation for Poiseuille flow seen below in Equation $3 .^{2}$

$$
\Delta p=R_{h y d} Q
$$

As seen in Equation 3, the Poiseuille flow equation requires a proportionality factor. The proportionality is the relation between pressure drop, $\Delta \mathrm{p}$, across a 
microchannel and the channel's volumetric flow rate, Q. ${ }^{2}$ This phenomenon is defined as $\mathrm{R}_{\text {hyd }}$, which is the hydraulic resistance of the channel. The resistance is dependent on the viscous shear stress between fluid and channel, causing a dissipation of energy. ${ }^{2}$ High fluidic resistance is observed in microfluidic chips, and is an important physical parameter to consider when designing microchannels. If a channel size was decreased by a factor of ten the fluidic resistance would increase by a factor of ten thousand. Equation 3 is a versatile and useful relation as it is applicable for non-Newtonian flows such as blood, urine, polymer solutions. ${ }^{2}$ 


\section{Chapter 2: COMSOL Multiphysics ${ }^{\circledR}$}

\subsection{Background}

COMSOL Multiphysics ${ }^{\circledR}$ is simulation software that utilizes finite element analysis to solve various physics and engineering phenomena. Due to the software's ability to couple a variety of phenomena into a single problem, the multiphysics facet of COMSOL Multiphysics ${ }^{\circledR}$ provides a versatile and robust environment for users.Below in Table IIshows all the different COMSOL Multiphysics ${ }^{\circledR}$ modules available.

Table II: COMSOL Multiphysics ${ }^{\circledR}$ available platforms with emphasis on the fluidic platform

\begin{tabular}{|c|c|c|c|}
\hline Chemical & Mechanical & Flud & Elec tric al \\
\hline $\begin{array}{l}\text { Chemical Reaction } \\
\text { Engineer ing Module }\end{array}$ & $\begin{array}{l}\text { Heat Transfer } \\
\text { Module }\end{array}$ & $\begin{array}{c}\text { CFD } \\
\text { Module }\end{array}$ & $\begin{array}{l}\text { ACDC } \\
\text { Module }\end{array}$ \\
\hline $\begin{array}{l}\text { Batteries and Fuel } \\
\text { Cetl Module }\end{array}$ & $\begin{array}{c}\text { Structura1 Mechanics } \\
\text { Module }\end{array}$ & $\begin{array}{l}\text { Microfluidics } \\
\text { Module }\end{array}$ & $\underset{\text { Module }}{\mathrm{RF}}$ \\
\hline $\begin{array}{c}\text { Electrodeposition } \\
\text { Module }\end{array}$ & $\begin{array}{c}\text { Nonlinear Structural } \\
\text { Materials Module }\end{array}$ & $\begin{array}{c}\text { Subsurface Flow } \\
\text { Module }\end{array}$ & $\begin{array}{l}\text { Wave Optics } \\
\text { Module }\end{array}$ \\
\hline Corrosion Madule & $\begin{array}{l}\text { Geomechanics } \\
\text { Module }\end{array}$ & $\begin{array}{l}\text { Pipe Flow } \\
\text { Module }\end{array}$ & $\begin{array}{l}\text { MEMS } \\
\text { Madule }\end{array}$ \\
\hline \multirow[t]{3}{*}{$\begin{array}{l}\text { Electrochemistry } \\
\text { Module }\end{array}$} & $\begin{array}{l}\text { Fatigve } \\
\text { Module }\end{array}$ & $\begin{array}{l}\text { Plasma } \\
\text { Module }\end{array}$ & $\begin{array}{l}\text { Plasma } \\
\text { Module }\end{array}$ \\
\hline & $\begin{array}{c}\text { Multibody Dynamics } \\
\text { Module }\end{array}$ & $\begin{array}{l}\text { Molecular Flow } \\
\text { Module }\end{array}$ & $\begin{array}{l}\text { Semiconductor } \\
\text { Module }\end{array}$ \\
\hline & $\begin{array}{l}\text { Acoustics } \\
\text { Module }\end{array}$ & & \\
\hline
\end{tabular}

The four categories are Chemical, Mechanical, Fluid, and Electrical with subset models within each major category. ${ }^{15}$ For this research, only modules under the main heading category, Fluid, were utilized. The two main modules utilized were the Microfluidics Module and the CFD Module. In Table II, there is an additional module boxed under the Electrical category, Micro-Electro-Mechanical Systems (MEMS). If a researcher were to model Electroosmostic flow, the MEMS model would be utilized. 
To begin simulating in COMSOL Multiphysics ${ }^{\circledR}$, the first step is to determine which module to use, the dimensions of the experiment, and defining the physics of the problem. For this thesis, the system's environment was defined as a laminar two-phase flow utilizing the level set method.An image of COMSOL Multiphysics ${ }^{\circledR}$ software can be seen in Figure 6. The model builder allows the user to define parameters, build within the software,define materials, adjust the physical properties, mesh, and view the results. This chapter will focus on the computational theory of the physics involved in this research, but the actual physical propertiesof the materials, flow parameters, and mesh will be discussed extensively in the chapter on Experimental Procedures.

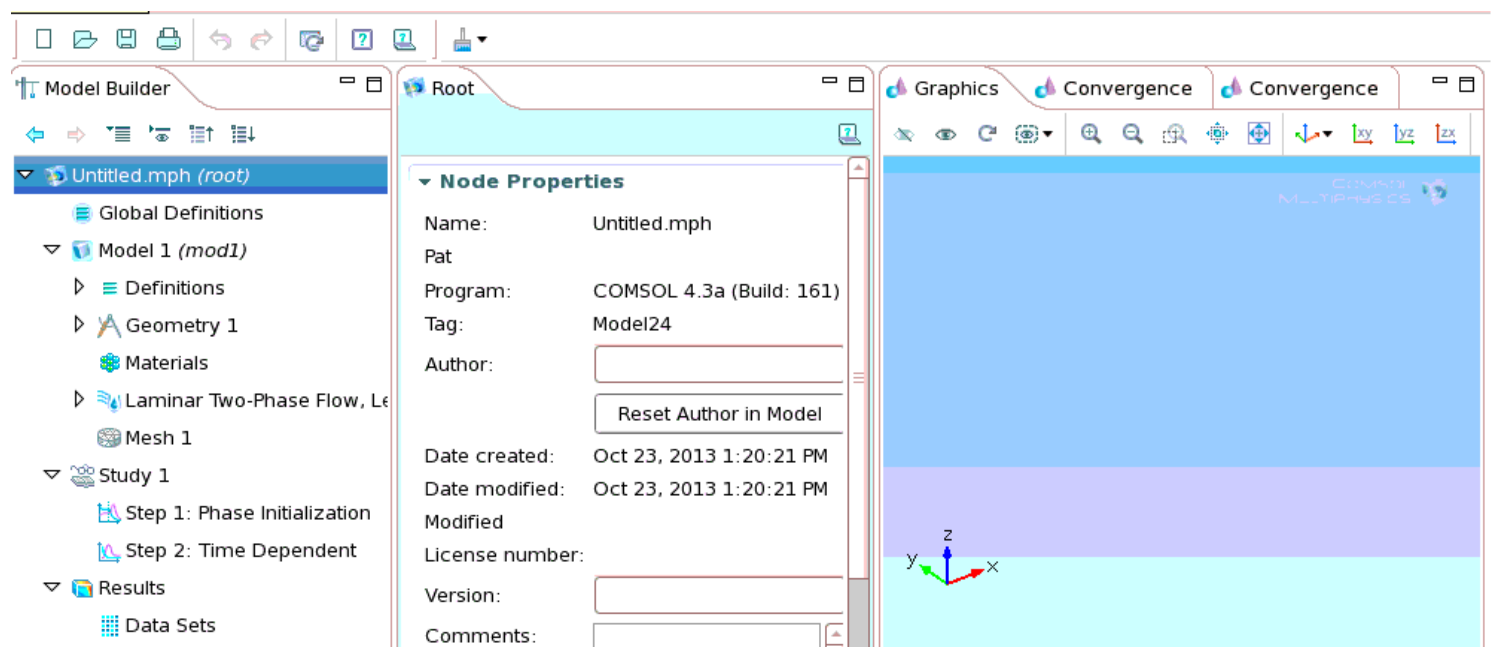

Figure 6: Image of the model builder, root, and graphics section of COMSOL Multiphysics ${ }^{\circledR}$ software package.

\subsection{Single Phase and Multiphase Flow}

Single phase flow is a less complicated system to computationally model than multiphase flow due to fewer partial differential equations that are required to be solved. 
Although computationally solving single phase systems may be simpler, by no means is this a quick simulation. There are still a number of equations to be solved.

When analyzing the motion of a fluid, the starting equation is the Navier-Stokes equation. The Navier-Stokes equations originate from the application of Newton's second law of motion to the actuation of fluid and area special case of the continuity equation. $^{2}$ The Navier-Stokes equations make the following assumptions: constant fluid density, a laminar flow regime exists throughout the system, a Newtonian fluid, and assume the three-dimensional stresses for a fluid obey Hooke's law. ${ }^{4}$ Assuming the above assumptions are true, the incompressible form of the Navier Stokes equation can be seen below in Equation 4.

$$
\rho \frac{d u}{d t}+\rho(u \cdot \nabla) u=\nabla \cdot\left[-p I+\mu\left(\nabla u+\nabla u^{T}\right)\right]+F_{g}+F_{s t}
$$

This subsection will be focusing solely on microfluidic flow. As previously discussed, the Reynolds number for microfluidic devices is very low, meaning that viscous forces dominate over inertial forces. Therefore, the inertial variables, $\rho(u \cdot \nabla) u$, are removed. At low Reynolds number and small length scales, the Bond number, a dimensionless number, becomes important. The Bond number relates the gravitational forces to surface tension forces. A low Bond number and small length scale provide a fluidic environment that has negligible gravitational force, $F_{g}$, and thereby surface tension forces dominate. As can be seen in Equation 5, the terms related to inertia and body forces has been removed from the equation.

$$
\rho \frac{d u}{d t}=\nabla \cdot\left[-p I+\mu\left(\nabla u+\nabla u^{T}\right)\right]+F_{s t}
$$


Up to this point, only the motion of a single phase of fluid has been discussed. However, in COMSOL Multiphysics ${ }^{\circledR}$, other modules can be coupled with this system. A couple examples of additional physical phenomena that have not been mentioned are diffusion, heat transport, and electric field.

Multiphase flow has all of the previously mentioned properties plus the following: boundary conditions at the fluid interface, contact angle, surface tension force, interfacial flows, and time-dependency. When computational modeling two-phase flow, another set of equations are necessary. The level set method is commonly utilized for multiphase simulations, and is described in the next section.

\subsection{Level Set Method}

The level set method is an accurate, simple, robust, and straightforward method for modeling multiphase flow. ${ }^{4}$ The level set method utilizes a smooth signed distance function to produce an interface. Figure 7 provides a visual example of the level set method. The level set variable is represented by $\Phi$. In Phase 1, the value of $\Phi$ in the dispersed phase is equivalent to one. At the interface, the region separating the two phases in Figure 7, the level set variable is equivalent to 0.5. Phase 2 is composed of the continuous fluid, and $\Phi$ equals zero. Although this method has many positive aspects, the major defect in this method is that mass is not conserved and significant mass loss may occur. ${ }^{4}$ 


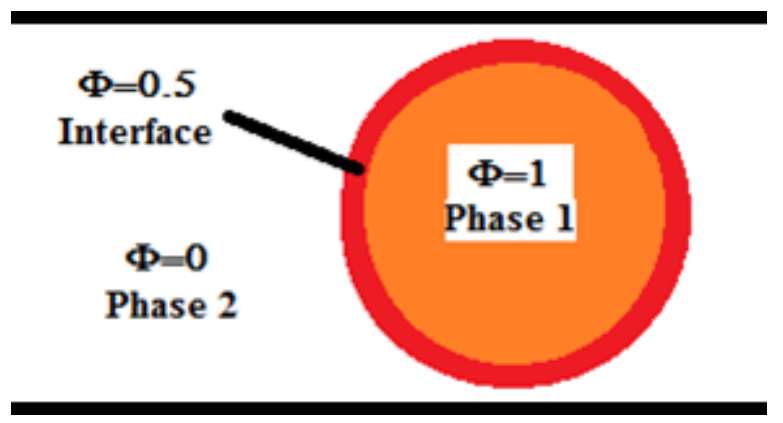

Figure 7:Schematic of a droplet flowing through a channel.Phase 1 is the dispersed phase and Trepresents the level set variable. The interface is the region between the two phases and Phase 2 is the continuous phase.

Although conservation of volume has become a concern when simulating, COMSOL Multiphysics ${ }^{\circledR}$ has recently provided a modified version of the level set method. ${ }^{16}$ This new method is a combination of the level set and the volume of fluid method. The volume of fluid method utilizes a discontinuous function that decreases the accuracy of the position of the interface and the curvature. This escalates to an inaccurate surface tension force, but the volume of fluid method conserves the mass exactly. ${ }^{16}$ By hybridizing the volume of fluid and level set methods, COMSOL Multiphysics ${ }^{\circledR}$ is able to accurately track the interface and conserve volume.

\subsection{Finite Element Modeling}

The finite element analysis is a numerical method to solve partial differential equations. The finite element method relies on meshing the spatial domain into multiple elements. A finer mesh with more elements provides a more accurate solution, but a finer mesh requires longer solving times than a cruder mesh. ${ }^{2,4}$ The finite element method utilizes an iterative processto calculate asolution to all couple field variables. 
When performing finite element modeling, the user must first build the geometry. Models, material properties, and boundary conditions are applied to the geometry and then meshed. Upon meshing, the computations begin. The major challenge is the successfully convergence of the algorithms, which then produces a solution. If the algorithms diverge, the user has no results. The user must then confirm all values are correctly entered or approach the problem from a different angle. A different approach may be to adjust the mesh or boundary conditions. 


\section{Chapter 3: Experimental Procedures}

Discussion of the experimental procedures is divided into two sections. The first three subsections focus on the three-dimensional microdroplets, and the next fivesubsections focus on the two-dimensional micronozzle. The subsections focus on geometric design and fluidic properties.The design of the three-dimensional microdroplet microfluidic device is split into two regions, T-junction and a pillar induced merging chamber.

\subsection{Three-Dimensional T-junction Design}

The three-dimensional T-junction is composed of two inlets. The inlet for Fluid 1 had a width of $100 \mu \mathrm{m}$ and a length of $200 \mu \mathrm{m}$ prior to the junction. The inlet for Fluid 2 had an inlet width of $100 \mu \mathrm{m}$ and length of $400 \mu \mathrm{m}$ prior to reaching the junction, as can be seen in Figure 8. Post T-junction, the droplets travel $700 \mu \mathrm{m}$ to the expanded pillar induced merging chamber. The entire geometry has a depth of $100 \mu \mathrm{m}$.

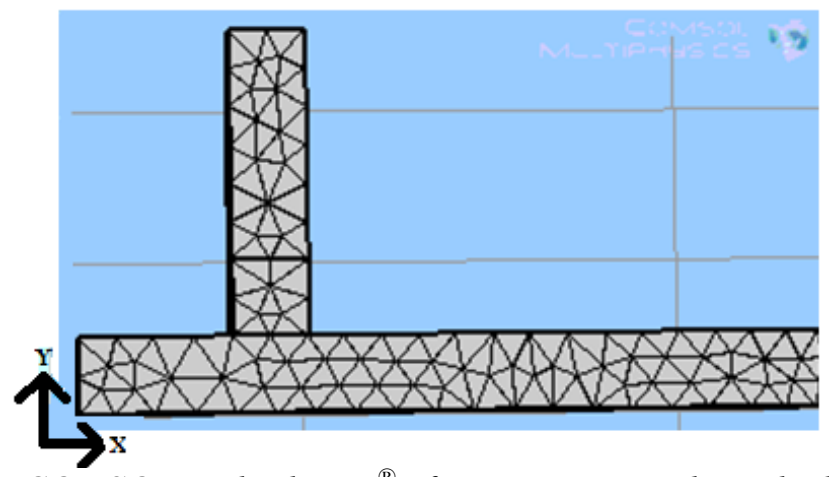

Figure 8: Image from COMSOL Multiphysics ${ }^{\circledR}$ of a T-junction with mesh elements applied to the geometry. Fluid will flow from left to right. The dispersed phase will enter through the vertical channel and the carrier phase will enter through the horizontal channel. 
A free tetrahedral mesh with a COMSOL Multiphysics ${ }^{\circledR}$ predetermined element size of "extra fine" was utilized. The maximum element size was $56.7 \mu \mathrm{m}$, and the minimum element size was $2.43 \mu \mathrm{m}$.

\subsection{Three-Dimensional Pillar Induced Merging Chamber Design}

The merging chamber was designed to retard droplets as they enter the chamber. The pillars would promote controlled droplet fusion. As can be seen in Figure 9, the pillars overlap the entrance and thereby create an internal channel for the droplets. Each pillar has a width of $20 \mu \mathrm{m}$ and a spacing of $20 \mu \mathrm{m}$ between each pillar. The length of the pillars increases from $24 \mu \mathrm{m}$ to $41 \mu \mathrm{m}$ as the fluid enters the chamber. The width of the channel that enters the merging chamber is $100 \mu \mathrm{m}$ and is equivalent to the outlet.

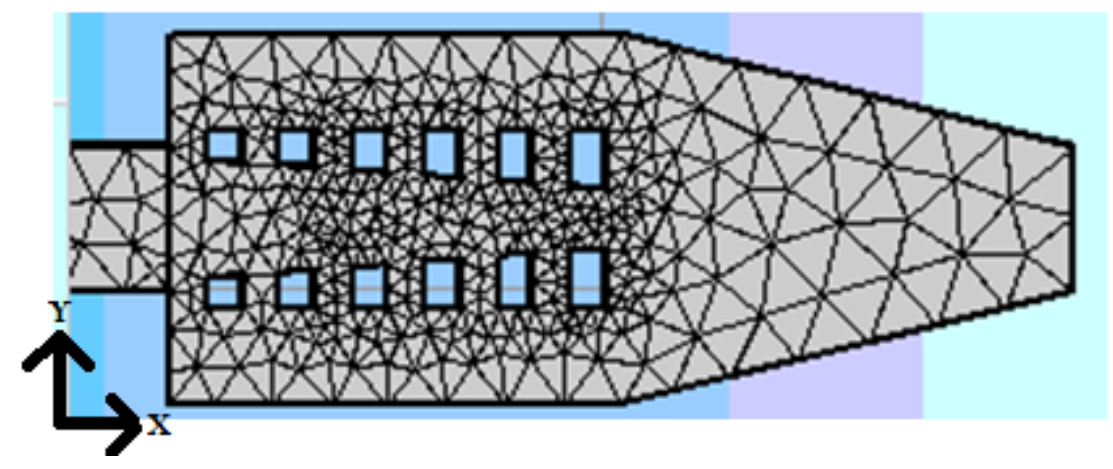

Figure 9: Image from COMSOL Multiphysics ${ }^{\circledR}$ of a pillar induced merging chamber with mesh elements applied to the geometry. The mesh elements are smaller near the pillars because the pillars are the region where the droplets will merge. More elements are required to accurately model the droplet fusion.

The meshing parameters used for the merging chamber are exactly the same as the three-dimensional T-junction. However, as can be seen in Figure 9, the mesh is finer near the pillars. Droplet merging is a much more complicated process than tracking droplet movement within a channel. When droplets merge, the computer has to track the 
boundary layers of each droplet as the two droplets merge into one. The droplet merging occurs as a result of the increasing pillar size within the expansion chamber. Therefore, more mesh elements are needed in the pillar region.

\subsection{Fluidic Properties of Three-Dimensional Microdroplets}

In Table III, the fluidic properties for the three-dimensional microdroplets are summarized. The values utilized in this research are from a COMSOL Multiphysics ${ }^{\circledR}$ simulation guide. $^{7}$

Table III: Fluidic Properties of the Three-Dimensional Microdroplets

\begin{tabular}{lccc}
\hline \multicolumn{1}{c}{ Variable } & Numerical Value & Units & Description \\
\hline $\mathrm{Q}_{\mathrm{F} 1}$ & 6.66 & $\mu \mathrm{l} / \mathrm{min}$ & carrier fluid \\
$\mathrm{Q}_{\mathrm{F} 2}$ & 3.33 & $\mu \mathrm{l} / \mathrm{min}$ & droplet \\
Viscosity-F1 & $1.958 \times 10^{-3}$ & $\mathrm{~Pa}^{*} \mathrm{~s}$ & carrier fluid \\
Viscosity-F2 & $6.71 \times 10^{-3}$ & $\mathrm{~Pa}^{*} \mathrm{~s}$ & droplet \\
Density-F1 & $1.00 \times 10^{3}$ & $\mathrm{~kg} / \mathrm{m}^{\wedge} 3$ & carrier fluid \\
Density-F2 & $1.00 \times 10^{3}$ & $\mathrm{~kg} / \mathrm{m}^{\wedge} 3$ & droplet \\
Interfacial Tension & $5.00 \times 10^{-3}$ & $\mathrm{~N} / \mathrm{m}$ & \\
Contact angle & 135 & Degrees & \\
Reynolds Number & $2.48 \times 10^{-1}$ & & \\
\hline
\end{tabular}

\subsection{Two-Dimensional Nozzle Geometries}

The design of the two-dimensional nozzle geometry is divided into the flow focusing junction, nozzle, and post nozzle geometry. There are three variables that can be altered in every simulation. The flow rate of the water, the nozzle width, and the design of the post nozzle geometry can be varied. 


\subsection{Two-Dimensional Flow Focusing Junction Design}

The flow focusing junction is the first stage in creating the nozzle geometries. Three separate channels, all $100 \mu \mathrm{m}$ wide and 1,000 $\mu \mathrm{m}$ long, merge at the flow focusing junction. An image of the three channels can be seen below in Figure 10. Water was introduced through the channel parallel to the abscissa, and oil was introduced through the two vertical channels.

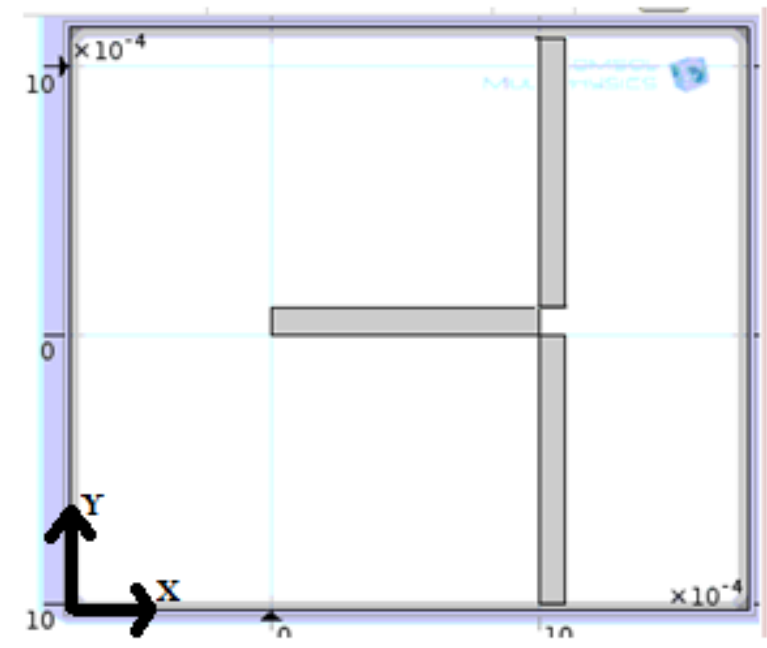

Figure 10: Image from COMSOL Multiphysics ${ }^{\circledR}$ of a flow focusing junction. In a flow focusing junction, three channels merge into one. The two vertical channels introduce oil into the microchannel which shears the water coming from the horizontal channel to form droplets.

\subsection{Two-Dimensional Nozzle}

The nozzle region of the geometries begins at $1,100 \mu \mathrm{m}$ and extends to $1,400 \mu \mathrm{m}$ along the abscissa. The narrowest point of the nozzle occurs at 1,250 $\mu \mathrm{m}$. Initially, the width of the channel is $100 \mu \mathrm{m}$ and then tapers to one of three separate widths 23,45 , or $100 \mu \mathrm{m}$ at $1,250 \mu \mathrm{m}$. After $1,250 \mu \mathrm{m}$, the nozzle then widens to $100 \mu \mathrm{m}$. On the following page,refer to Figure 11 to view the three separate nozzle widths. 

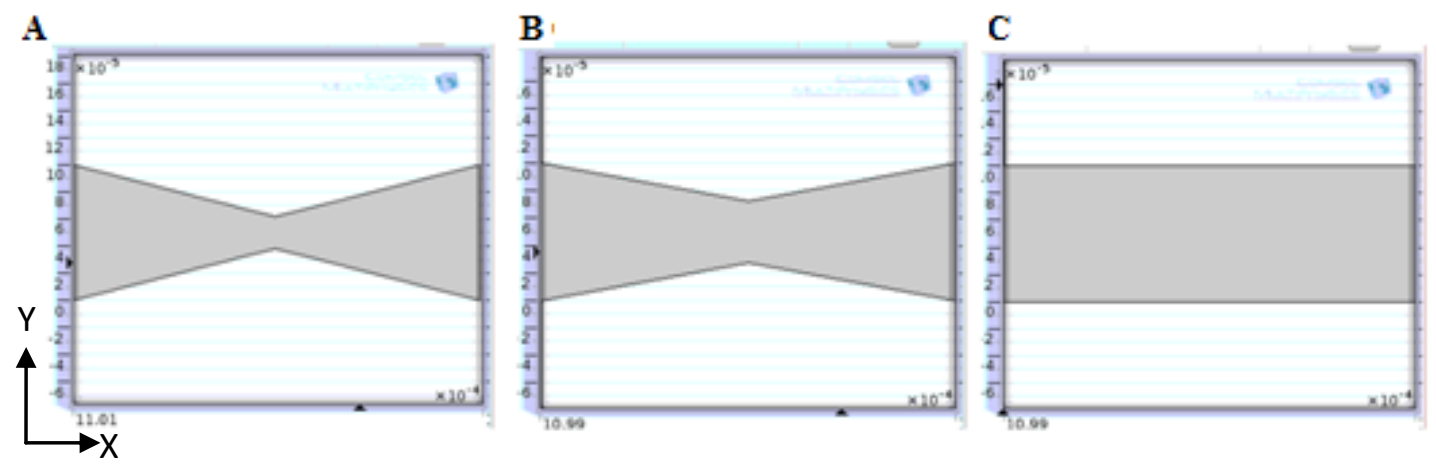

Figure 11: Images from COMSOL Multiphysics ${ }^{\circledR}$ of nozzles with throat width of $A-23 \mu \mathrm{m}, B$ $45 \mu \mathrm{m}$, and C-100 $\mu \mathrm{m}$. In the simulation, the fluid flows from left to right.

\subsection{Two-Dimensional Post-Nozzle Geometry}

There are four separate post-nozzle geometry designs: straight; gradual, abrupt, and 90 degrees. The gradual, abrupt, and 90 degree designs have expansion chambers. The straight design has no expansion chamber. The gradual, abrupt, and 90 degree designs describe the geometry as the fluid is introduced to the expansion chamber.

The straight channel is the simplest design, as it is a continuation of the initial channel with a length of $2,000 \mu \mathrm{m}$ and width of $100 \mu \mathrm{m}$. An image of a straight channel is provided below in Figure 12.

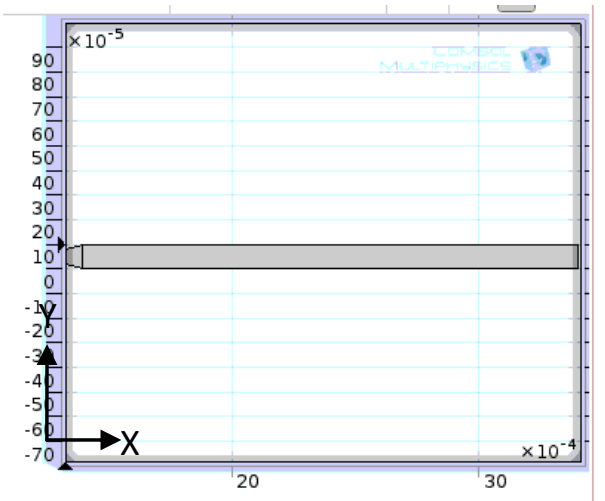

Figure 12: Image from COMSOL Multiphysics ${ }^{\circledR}$ of a straight channel post nozzle geometry.In the simulation, the fluid flows from left to right. 
The abrupt post nozzle geometry is a blunter approach into the expansion chamber. The abrupt approach into the expansion chamber occurs over a length of 250 $\mu \mathrm{m}$, and at an angle of $38.66^{\circ}$. The expansion channel has a length of $2,000 \mu \mathrm{m}$ and is $400 \mu \mathrm{m}$ wide. An image of the abrupt channel can be seen below in Figure 13.

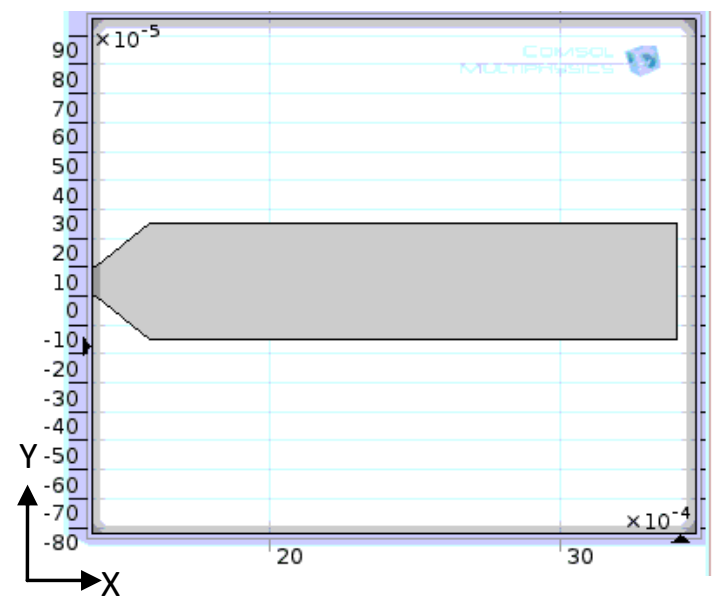

Figure 13: Image from COMSOL Multiphysics ${ }^{\circledR}$ of an abrupt post nozzle geometry. In the simulation, the fluid flows from left to right.

The 90 degree post nozzle has no approach into the expansion chamber. The expansion channel has a length of $3,000 \mu$ mand is $400 \mu \mathrm{m}$ wide. Below, in Figure 14,is an image of the 90 degree post nozzle geometry.

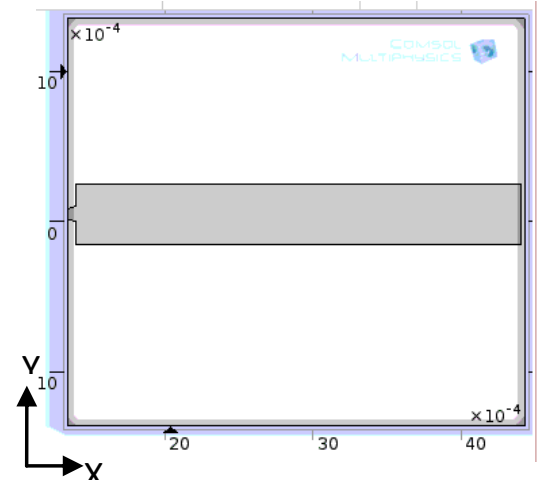

Figure 14: Image from COMSOL Multiphysics ${ }^{\circledR}$ of a 90 degree post nozzle geometry.In the simulation, the fluid flows from left to right. 
The gradual post nozzle geometry is a steady moderate approach into the expansion chamber. The approach into the expansion chamber occurs over a length of $1,100 \mu \mathrm{m}$, and at an angle of $7.77^{\circ}$. The expansion channel has a length of $2,000 \mu \mathrm{m}$ and is $400 \mu \mathrm{m}$ wide. Below, in Figure 15, is an image of gradual post nozzle geometry.

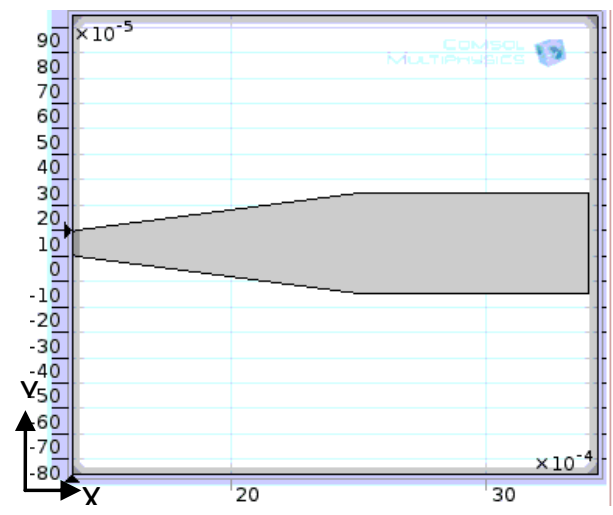

Figure 15: Image from COMSOL Multiphysics ${ }^{\circledR}$ of a gradual post nozzle geometry. In the simulation, the fluid flows from left to right.

\subsection{Two-Dimensional Nozzle Fluid Properties}

The properties of the fluids utilized in the two-dimensional studies can be seen below in Table IV. The flow rate of water is not constant, but varies from $55.44 \mathrm{X} 10^{-}$ ${ }^{4} \mathrm{ml} / \mathrm{hr}$ to $0.1 \mathrm{ml} / \mathrm{hr}$. The variables for the oil are similar to sunflower oil.

Table IV: Two-Dimensional Nozzle Fluid Properties

\begin{tabular}{lccc}
\hline \multicolumn{1}{c}{ Variable } & Numerical Value & Units & Description \\
\hline $\mathrm{Q}_{\mathrm{o}}$ & 0.1 & $\mathrm{ml} / \mathrm{hr}$ & carrier fluid \\
$\mathrm{Q}_{\mathrm{w}}$ & $55.44 \times 10^{-4}$ to 0.1 & $\mathrm{ml} / \mathrm{hr}$ & droplet \\
Viscosity Oil & $6.22 \times 10^{-2}$ & $\mathrm{~Pa}^{*} \mathrm{~s}$ & carrier fluid \\
Density Oil & $9.09 \times 10^{2}$ & $\mathrm{~kg} / \mathrm{m}^{\wedge} 3$ & carrier fluid \\
Viscosity Water & $1.002 \times 10^{-3}$ & $\mathrm{~Pa}^{*} \mathrm{~s}$ & droplet \\
Density Water & $10 \times 10^{2}$ & $\mathrm{~kg} / \mathrm{m}^{\wedge} 3$ & droplet \\
Interfacial Tension & $24 \times 10^{-3}$ & $\mathrm{~N} / \mathrm{m}$ & \\
Contact Angle & 100 & Degrees & \\
Reynolds Number & $9.34 \times 10^{-4}$ & & \\
\hline
\end{tabular}


The values utilized in the two-dimensional nozzle studies came from two sources. The first source was the deMello group from ETH in Zurich, co-collaborators on this work. ${ }^{6}$ The second source was a group from Japan who study the experimental and computational aspects of microfluidic nozzles. ${ }^{18}$ 


\section{Chapter 4: Two-Dimensional CFD Analysis of Nozzles}

The two-dimensional project was designed to supplement experimental research performed by deMello's group. The group constructed a couple of microfluidic devices with varying nozzles. The focus of the computational aspect of this research was to computationally characterize a variety of micronozzle widths and post nozzle geometries.

The simulations are grouped according to four different post nozzle designs: 90 , gradual, abrupt, and straight. Within each design, three separate nozzle widths are used: 23,45 , and $100 \mu \mathrm{m}$.

\subsection{Degree Post Nozzle Geometry}

The 90 degree post nozzle geometry has no introduction into the expansion channel. In regards to constructing the microfluidic chips, this would be the second simplest design, after the straight channel. The 90 degree post nozzle geometry was very successful in terms of droplet generation. Figure 16 illustrates the 90 degree geometry combined with three various nozzle widths.

An oil to water ratio of 5:1 and 6:1 were found to be the most optimal ratios for producing droplets. When viewing the images in Figure 16, the droplets are shown to break at different points throughout the post nozzle geometry. This is partially due to the different nozzle widths, but the images selected were also taken at different times. 

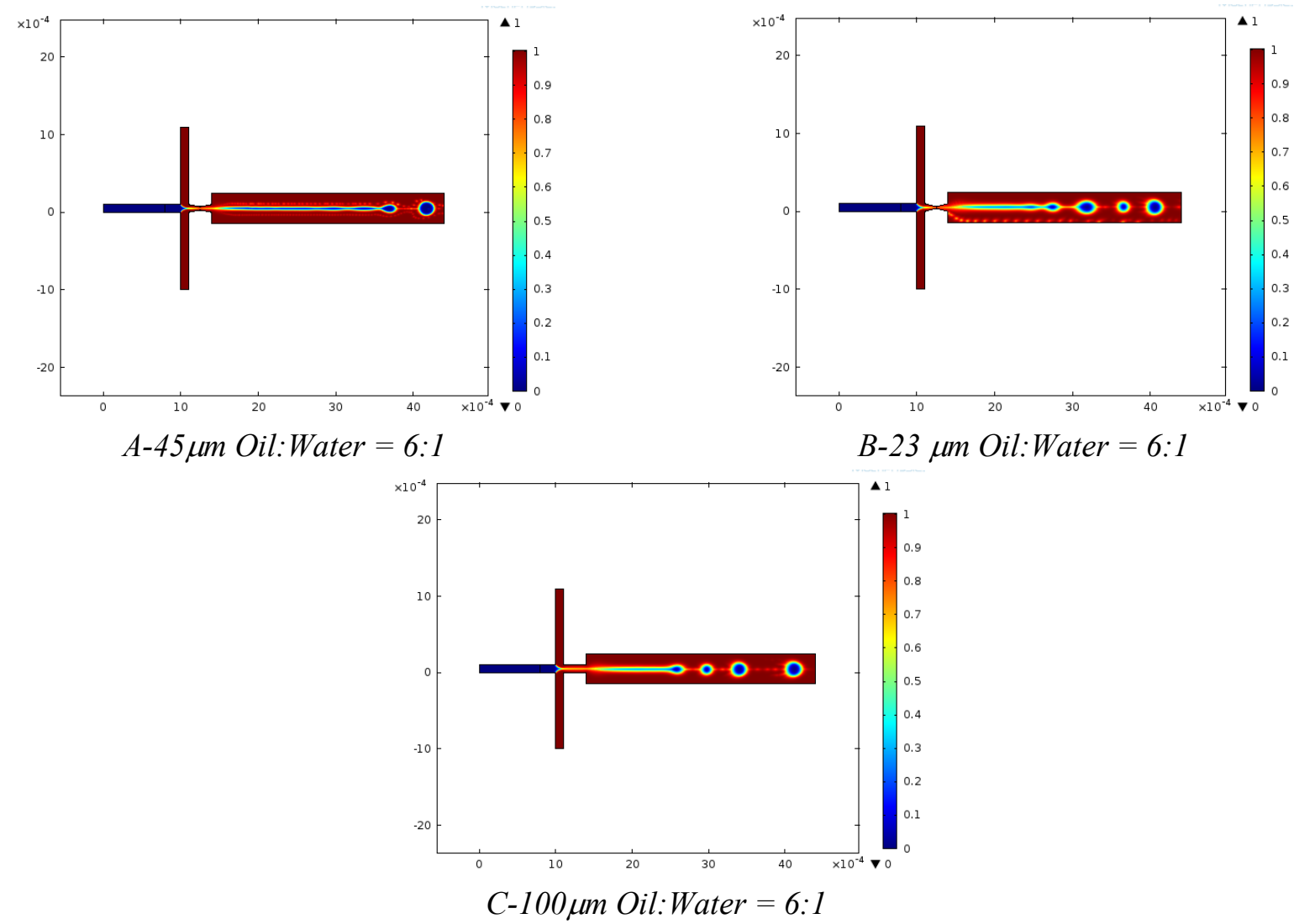

Figure 16: Images from COMSOL Multiphysics ${ }^{\circledR}$ of a 90 degree post nozzle geometry with throat

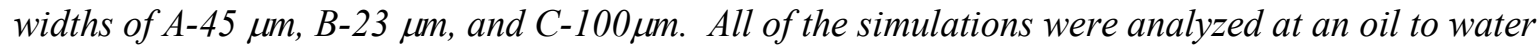
ratio of 6:1. The throat width affects the droplet formation mechanism. In Figure 16A, the droplets are formed at the end of the channel. In Figure 16B and Figure 16C, the droplets are formed earlier in the channel.

When analyzing the video of the droplets breaking up, occasionally droplets drip off, similar to Figure 16A. When the droplets drip off, the droplets are consistently the same size. However, there are instances where a series of droplets of a variety of sizes will break of simultaneously, similar to those seen in Figure 16B and Figure 16C.

In Figure 16B, a small series of droplets can be observed in the post nozzle geometry beneath the main fluid stream and droplets. This instability was observed in all of the simulations with a nozzle width of $23 \mu \mathrm{m}$. The geometric design and meshing elements of the nozzle and post nozzle geometry were double checked to confirm that an 
asymmetric mesh was not constructed. The nozzle and the post nozzle geometries were symmetric and the very small droplets were not a result of an asymmetrical design. The mesh utilized was an extra fine triangular mesh that appeared symmetric.

As can be seen in Figure 17, when analyzing the pressure in the system, as anticipated, the highest pressure occurs prior to the fluid entering the nozzle. At the narrowest point of the nozzle, the largest pressure drop occurs. This is a result of the pressure gradient as fluid flows from a high pressure region, fluid inlets, to a low pressure region, post-nozzle geometry.

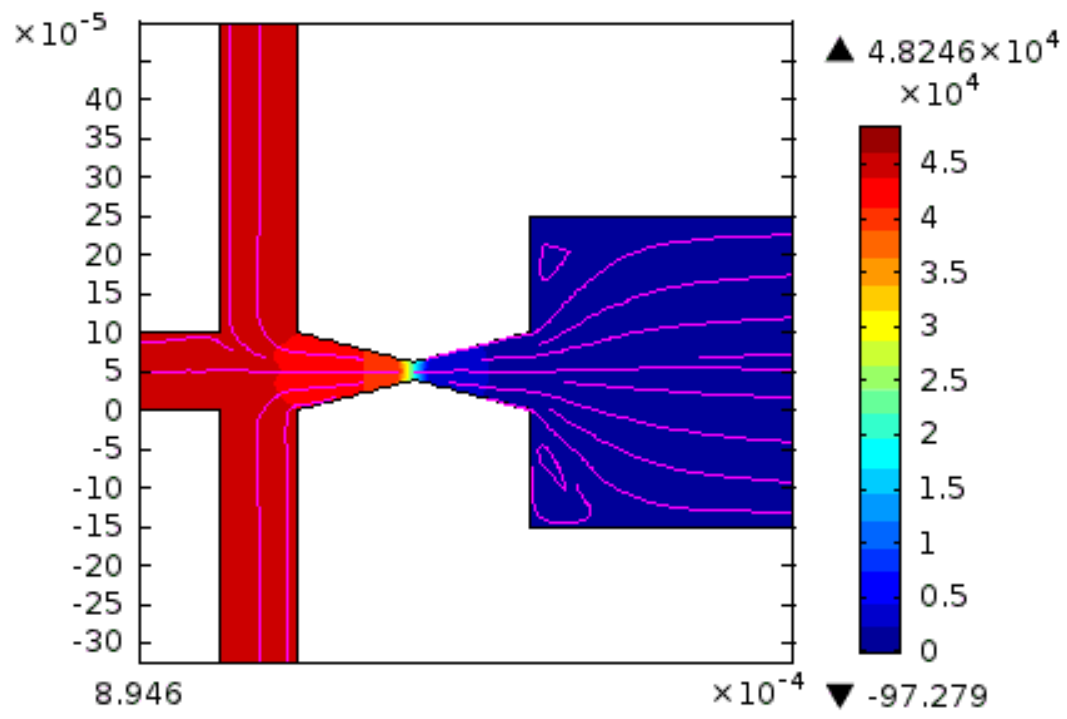

Figure 17: Image from COMSOL Multiphysics ${ }^{\circledR}$ of streamlines from a 90 degree post nozzle geometry with a nozzle width of $23 \mu \mathrm{m}$.In the image, fluid is flowing from left to right. The image illustrates the pressure in the system. The highest pressure is observed just before the fluid enters the narrowest point of the channel, the nozzle. The largest pressure drop at the narrowest point of the nozzle, as the fluid flows from a high pressure region, flow focusing junction, to a lower pressure region, the expansion chamber.

In Figure 17, two stagnation regions can be seen in each corner of the 90 degree channel. The stagnation region is expected in the corners, but the stagnation points are 
not symmetric. The most likely culprit for the small droplets observed in the bottom portion of the channel is a numerical instability within COMSOL Multiphysics ${ }^{\circledR}$ and not a physical phenomenon.

A compilation of all simulations examined with a 90 degree post nozzle geometry can be seen in Table V. This design resulted in a large number of experiments that formed droplets. $\mathrm{Q}_{\mathrm{o}}: \mathrm{Q}_{\mathrm{w}}$ is the volumetric flow rate ratio of oil to water. For these experiments, the oil was held constant and the volume of the water was decreased.

At oil to water ratios of $4: 1$ and 5:1, droplets began to form. Simulations were carried out until droplets were becoming indistinguishable from each other. This varied by nozzle widths, but generally occurred at approximate ratios ranging from 12:1 to 18:1. Some experiments were continued past 18:1, but droplets became so small and inconsistent that it became challenging to define the "specks" as droplets.

Table V: Simulation Lists of 90 Degree Post Nozzle Geometry

\begin{tabular}{cccc}
\hline Qo:Qw & $23 \mu m$ & Nozzle Widths & \\
\hline 1 & No Drops & No Drops & No Drops \\
2 & No Drops & No Drops & No Drops \\
3 & No Drops & No Drops & No Drops \\
4 & No Drops & No Drops & Drops \\
5 & Drops & Drops & Drops \\
6 & Drops & Drops & Drops \\
7 & Drops & Drops & Drops \\
8 & Drops & Drops & Drops \\
9 & Drops & Drops & Drops \\
10 & Drops & Drops & Drops \\
11 & Drops & Drops & Drops \\
12 & Drops & Drops & Drops \\
13 & Drops & Drops & Drops \\
14 & Drops & Drops & Drops \\
15 & Drops & Drops & Drops \\
16 & Drops & Drops & Drops \\
17 & Drops & Drops & Indistinguishable \\
18 & Indistinguishable & Indistinguishable & \\
\hline
\end{tabular}




\subsection{Straight Post Nozzle Geometry}

The straight post nozzle geometry has no expansion channel. This post nozzle geometry was the simplest in design, but was the least successful geometry. Jetting was the most frequent phenomenon observed in the straight post nozzle geometry. At oil to water ratios over 7:1 inconsistent and indistinguishable drops occur. In Figure 18A is an illustration of jetting. No droplets occur with jetting, only a solid stream of fluid. Figure $18 \mathrm{~B}$ is an example of indistinguishable droplet generation. As can be seen, many small droplets occur, but at this point they are too small and indistinguishable to be useful.

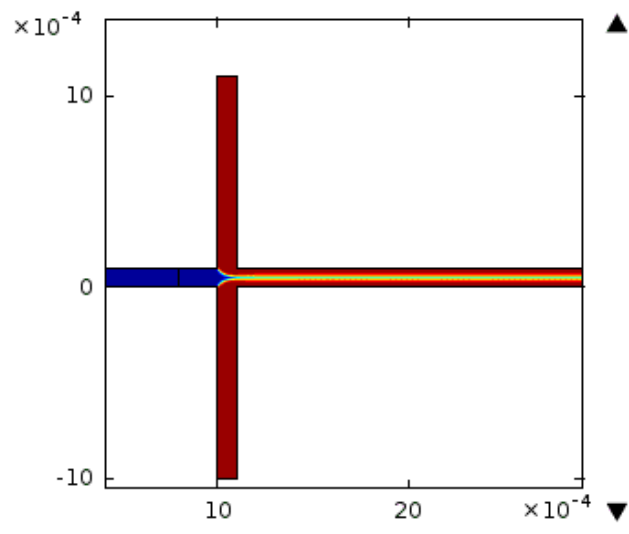

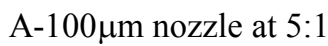

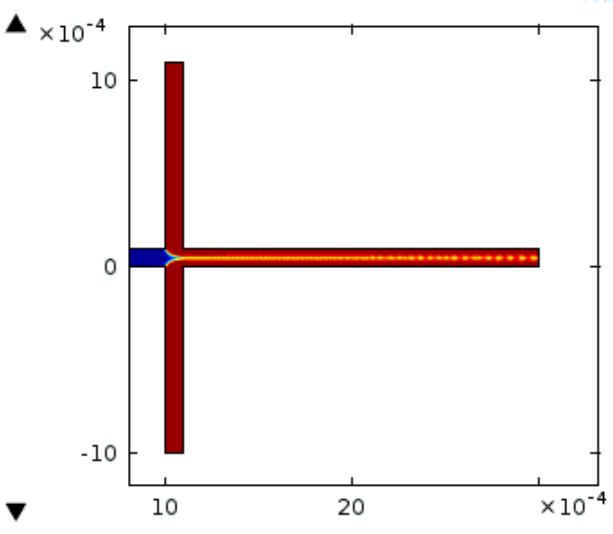

B-100 $\mu \mathrm{m}$ nozzle at 9:1

Figure 18: Images from COMSOL Multiphysics ${ }^{\circledR}$ of a $100 \mu$ mozzle with a straight channel post nozzle geometry. Figure $18 \mathrm{~A}$ illustrates jetting within a microchannel which results in no droplet formation. In Figure 18B, tiny indistinguishable droplets are formed.

As previously stated, the straight nozzle geometry was the least successful. In

Table VI is a compilation of all simulations utilizing the straight post nozzle geometry. Each nozzle width was simulated at ten different ratios. Of the 27 simulations, only two of those yielded droplets, ratios of 5:1 and 6:1. This post nozzle design would not be suggested for fabrication to test experimentally. 
TableVI: Simulation Lists of Straight Post Nozzle Geometry

\begin{tabular}{lccc}
\hline & & Nozzle Widths & \\
$Q o: Q w$ & $23 \mu m$ & $45 \mu m$ & $100 \mu m$ \\
\hline 1 & No Drops & No Drops & No Drops \\
2 & No Drops & No Drops & No Drops \\
3 & No Drops & No Drops & No Drops \\
4 & No Drops & No Drops & No Drops \\
5 & No Drops & Drops & No Drops \\
6 & No Drops & Drops & No Drops \\
7 & No Drops & Indistinguishable & No Drops \\
8 & No Drops & & No Drops \\
9 & No Drops & & No Drops \\
10 & No Drops & & Indistinguishable \\
\hline
\end{tabular}

\subsection{Abrupt Post Nozzle Geometry}

The abrupt post nozzle geometry is a less dramatic approach, 38.66 degree angle into the expansion chamber, relative to the 90 degree post nozzle geometry. The two most challenging designs to fabricate would be the abrupt and gradual post nozzle geometries.The abrupt post nozzle geometry was successful. As can be seen in Table VII, the $45 \mu \mathrm{m}$ and $100 \mu \mathrm{m}$ nozzles combined with the abrupt post nozzle geometry yielded drops from oil to water ratios, Qo:Qw, of 6:1 to 21:1. At 22:1 the droplets had become indistinguishable. No further simulations were analyzed.

Unfortunately, the nozzle with a width of $23 \mu \mathrm{m}$ was not a good fit with the abrupt post nozzle geometry. No droplets were formed with the combination of $23 \mu \mathrm{m}$ and the abrupt post nozzle geometry. 
Table VII: Simulation Lists of Abrupt Post Nozzle Geometry

\begin{tabular}{cccc}
\hline & & Nozzle Widths & \\
Qo:Qw & $23 \mu m$ & $45 \mu m$ & $100 \mu m$ \\
\hline 1 & No Drops & No Drops & No Drops \\
2 & No Drops & No Drops & No Drops \\
3 & No Drops & No Drops & No Drops \\
4 & No Drops & No Drops & No Drops \\
5 & No Drops & No Drops & No Drops \\
6 & No Drops & Drops & No Drops \\
7 & No Drops & Drops & Drops \\
8 & No Drops & Drops & Drops \\
9 & No Drops & Drops & Drops \\
10 & No Drops & Drops & Drops \\
11 & Indistinguishable & Drops & Drops \\
12 & & Drops & Drops \\
13 & & Drops & Drops \\
14 & & Drops & Drops \\
15 & & Drops & Drops \\
16 & & Drops & Drops \\
17 & & Drops & Drops \\
18 & & Drops & Drops \\
19 & & Drops & Drops \\
20 & & Drops & Drops \\
21 & & Drops & Drops \\
22 & & Indistinguishable & Indistinguishable \\
\hline
\end{tabular}

\subsection{Gradual Post Nozzle Geometry}

The gradual post nozzle geometry is the least dramatic approach with an angle of $7.77^{\circ}$ into the expansion chamber. As can be seen on the following page in Table VIII, the gradual post nozzle geometry was a very versatile post nozzle geometry that successfully generated droplets with all of the nozzle widths. Similar to the abrupt post nozzle geometry, simulations were stopped at 19:1 because the droplets became indistinguishable.

This post nozzle geometry is complementary with all nozzle widths. Although, this would be a challenging design, it would be worthwhile to experimentally fabricate the gradual post nozzle geometry. 
Table VIII: Simulation Lists of Gradual Post Nozzle Geometry

\begin{tabular}{lccc}
\hline & & Nozzle Widths & \\
Qo:Qw & $23 \mu m$ & $45 \mu m$ & $100 \mu m$ \\
\hline 1 & No Drops & No Drops & No Drops \\
2 & No Drops & No Drops & No Drops \\
3 & No Drops & No Drops & No Drops \\
4 & No Drops & No Drops & No Drops \\
5 & No Drops & Drops & No Drops \\
6 & No Drops & Drops & Drops \\
7 & Drops & Drops & Drops \\
8 & Drops & Drops & Drops \\
9 & Drops & Drops & Drops \\
10 & Drops & Drops & Drops \\
11 & Drops & Drops & Drops \\
12 & Indistinguishable & Drops & Drops \\
13 & & Drops & Drops \\
14 & & Drops & Drops \\
15 & & Drops & Drops \\
16 & & Drops & Drops \\
17 & & Drops & Drops \\
18 & & Drops & Drops \\
19 & & Indistinguishable & Indistinguishable \\
\hline
\end{tabular}

\subsection{Computational Validation}

All physical parameters were provided by the deMello group. The first simulations constructed had a nozzle width of $45 \mu \mathrm{m}$. The straight channel and 90 degree post nozzle geometries were validated against experimental channels fabricated by the deMello group.

Throughout the study, a file would be computationally analyzed twice to confirm that the same solution resulted for each simulation. Since this research is qualitative at this point, the only validation the deMello group required was a binary response on whether or not a droplet was form.

All other simulations are purely theoretical at this point and they have no experimental data to corroborate their authenticity. Experimental fabrications have not 
yet been performed, as that aspect of this research project is dependent on results from this study.

\subsection{Summary}

In conclusion, the nozzle and post nozzle characterization were very successful in that complementary and non-complimentary nozzle widths and post-nozzle geometries were identified. The least successful nozzle was the nozzle with a width of $23 \mu \mathrm{m}$ and the straight post nozzle geometry was the least successful nozzle.

A visual summary of all the simulations that were analyzed can be seen in Table IX. The results are grouped according to post nozzle geometry with sub-groups representing the nozzle widths. The values from the figure count for every simulation that generated droplets (104 simulations) out of the 185 simulations analyzed. The optimal range for droplet generation is at Qo:Qw ranging from 8 to 11 . In Table IX, the summary has three different variables that are used. The "N" represents no droplet formed, the "D" represents successful droplet formation, and "I" represents droplets that were indistinguishable. 
Table IX: Summary of Droplet Formation from all Simulations

\begin{tabular}{|c|c|c|c|c|c|c|c|c|c|c|c|c|}
\hline \multirow[b]{2}{*}{$Q o: Q w$} & \multicolumn{3}{|c|}{$\begin{array}{c}\text { Straight } \\
\text { Nozzle }(\mu \mathrm{m})\end{array}$} & \multicolumn{3}{|c|}{$\begin{array}{c}\text { Gradual Nozzle } \\
(\mu \mathrm{m})\end{array}$} & \multicolumn{3}{|c|}{$\begin{array}{c}\text { Abrupt } \\
\text { Nozzle }(\mu \mathrm{m})\end{array}$} & \multicolumn{3}{|c|}{$\begin{array}{c}\text { 90Degree } \\
\text { Nozzle }(\mu \mathrm{m})\end{array}$} \\
\hline & 23 & 45 & 100 & 23 & 45 & 100 & 23 & 45 & 100 & 23 & 45 & 100 \\
\hline 1 & $\mathrm{~N}$ & $\mathrm{~N}$ & $\mathrm{~N}$ & $\mathrm{~N}$ & $\mathrm{~N}$ & $\mathrm{~N}$ & $\mathrm{~N}$ & $\mathrm{~N}$ & $\mathrm{~N}$ & $\mathrm{~N}$ & $\mathrm{~N}$ & $\mathrm{~N}$ \\
\hline 2 & $\mathrm{~N}$ & $\mathrm{~N}$ & $\mathrm{~N}$ & $\mathrm{~N}$ & $\mathrm{~N}$ & $\mathrm{~N}$ & $\mathrm{~N}$ & $\mathrm{~N}$ & $\mathrm{~N}$ & $\mathrm{~N}$ & $\mathrm{~N}$ & $\mathrm{~N}$ \\
\hline 3 & $\mathrm{~N}$ & $\mathrm{~N}$ & $\mathrm{~N}$ & $\mathrm{~N}$ & $\mathrm{~N}$ & $\mathrm{~N}$ & $\mathrm{~N}$ & $\mathrm{~N}$ & $\mathrm{~N}$ & $\mathrm{~N}$ & $\mathrm{~N}$ & $\mathrm{~N}$ \\
\hline 4 & $\mathrm{~N}$ & $\mathrm{~N}$ & $\mathrm{~N}$ & $\mathrm{~N}$ & $\mathrm{~N}$ & $\mathrm{~N}$ & $\mathrm{~N}$ & $\mathrm{~N}$ & $\mathrm{~N}$ & $\mathrm{~N}$ & $\mathrm{~N}$ & $\mathrm{D}$ \\
\hline 5 & $\mathrm{~N}$ & D & $\mathrm{N}$ & $\mathrm{N}$ & D & $\mathrm{N}$ & $\mathrm{N}$ & $\mathrm{N}$ & $\mathrm{N}$ & $\mathrm{D}$ & $\mathrm{D}$ & $\mathrm{D}$ \\
\hline 6 & $\mathrm{~N}$ & D & $\mathrm{N}$ & $\mathrm{N}$ & D & $\mathrm{D}$ & $\mathrm{N}$ & $\mathrm{D}$ & $\mathrm{N}$ & $\mathrm{D}$ & $\mathrm{D}$ & $\mathrm{D}$ \\
\hline 7 & $\mathrm{~N}$ & I & $\mathrm{N}$ & $\mathrm{D}$ & D & $\mathrm{D}$ & $\mathrm{N}$ & D & $\mathrm{D}$ & $\mathrm{D}$ & $\mathrm{D}$ & $\mathrm{D}$ \\
\hline 8 & $\mathrm{~N}$ & & $\mathrm{~N}$ & D & D & $\mathrm{D}$ & $\mathrm{N}$ & D & $\mathrm{D}$ & $\mathrm{D}$ & $\mathrm{D}$ & $\mathrm{D}$ \\
\hline 9 & $\mathrm{~N}$ & & $\mathrm{~N}$ & D & D & $\mathrm{D}$ & $\mathrm{N}$ & D & $\mathrm{D}$ & $\mathrm{D}$ & $\mathrm{D}$ & $\mathrm{D}$ \\
\hline 10 & $\mathrm{~N}$ & & I & D & D & $\mathrm{D}$ & $\mathrm{N}$ & $\mathrm{D}$ & $\mathrm{D}$ & $\mathrm{D}$ & $\mathrm{D}$ & $\mathrm{D}$ \\
\hline 11 & & & & D & D & $\mathrm{D}$ & I & D & $\mathrm{D}$ & $\mathrm{D}$ & $\mathrm{D}$ & $\mathrm{D}$ \\
\hline 12 & & & & I & $\mathrm{D}$ & $\mathrm{D}$ & & $\mathrm{D}$ & $\mathrm{D}$ & $\mathrm{D}$ & $\mathrm{D}$ & $\mathrm{D}$ \\
\hline 13 & & & & & D & $\mathrm{D}$ & & D & $\mathrm{D}$ & $\mathrm{D}$ & $\mathrm{D}$ & $\mathrm{D}$ \\
\hline 14 & & & & & D & $\mathrm{D}$ & & D & $\mathrm{D}$ & $\mathrm{D}$ & $\mathrm{D}$ & $\mathrm{D}$ \\
\hline 15 & & & & & D & $\mathrm{D}$ & & D & $\mathrm{D}$ & $\mathrm{D}$ & $\mathrm{D}$ & $\mathrm{D}$ \\
\hline 16 & & & & & D & $\mathrm{D}$ & & D & $\mathrm{D}$ & $\mathrm{D}$ & $\mathrm{D}$ & $\mathrm{D}$ \\
\hline 17 & & & & & D & $\mathrm{D}$ & & $\mathrm{D}$ & $\mathrm{D}$ & $\mathrm{D}$ & $\mathrm{D}$ & I \\
\hline 18 & & & & & $\mathrm{D}$ & $\mathrm{D}$ & & $\mathrm{D}$ & $\mathrm{D}$ & I & I & \\
\hline 19 & & & & & I & I & & D & D & & & \\
\hline 20 & & & & & & & & D & $\mathrm{D}$ & & & \\
\hline 21 & & & & & & & & $\mathrm{D}$ & $\mathrm{D}$ & & & \\
\hline 22 & & & & & & & & I & $\mathrm{I}$ & & & \\
\hline
\end{tabular}




\section{Chapter 5: Three-Dimensional Segmented Flow}

The three-dimensional project was designed to supplement computational research performed by the deMello group. The group performed a computational twodimensional analysis on droplet generation and merging in a microfluidic chip, and then extended this study to a three-dimensional analysis.

\subsection{T-junction Verification}

The first step in constructing this simulation is generating droplets. Droplet generation commonly occurs by shearing one fluid phase with another. The simulation file, Droplet Breakup in a T-junction, supplied by COMSOL Multiphysics ${ }^{\circledR}$ provides the physical parameters that can be seen Table III of Chapter $3 .{ }^{17}$ This practice file was the starting point for constructing the three-dimensional geometries. Utilizing the $\mathrm{T}$-junction COMSOL Multiphysics ${ }^{\circledR}$ file, the merging chamber with pillars was added on to the Tjunction. Although the T-junction was not a replica of the experimental droplets and two-dimensional analyses, the T-junction successfully generated droplets.

The major difference between the three-dimensional design and the twodimensional design that was constructed by the deMello group is the manner in which the droplets are generated. A flow focusing junction similar to the one designed by the deMello group can be seen in Figure 19. T-junctions and flow focusing junctions generate droplets by shearing one phase with another. 


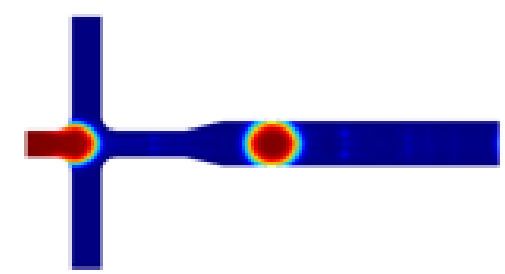

Figure 19: Image from COMSOL Multiphysics ${ }^{\circledR}$ of a flow focusing junction. A single droplet is flowing through an enlarged channel. Another droplet is beginning to form at the intersection of the three inlets.

To verify the versatility of the T-junction, the T-junction's geometric design and fluid flow rate were modified to replicate experimentaland computational research performed by a group in the Netherlands. van Steijn and co-workers validated a variety of channel heights, depths, widths, and flow rates. ${ }^{19}$ With these validations; they were able to provide specific parameters and boundaries for successfully droplet generation. In Figure 20, the dimensionless volume, $\mathrm{V} /\left(\mathrm{hw}^{2}\right)$, of droplets are plotted against the ratio of flow rates, $\mathrm{q}_{\mathrm{c}}$ and $\mathrm{q}_{\mathrm{d}}$, which are the carrier and dispersed phase, respectively. The volume, height, and width of the channel are represented by $\mathrm{V}, \mathrm{h}$, and w, respectively.
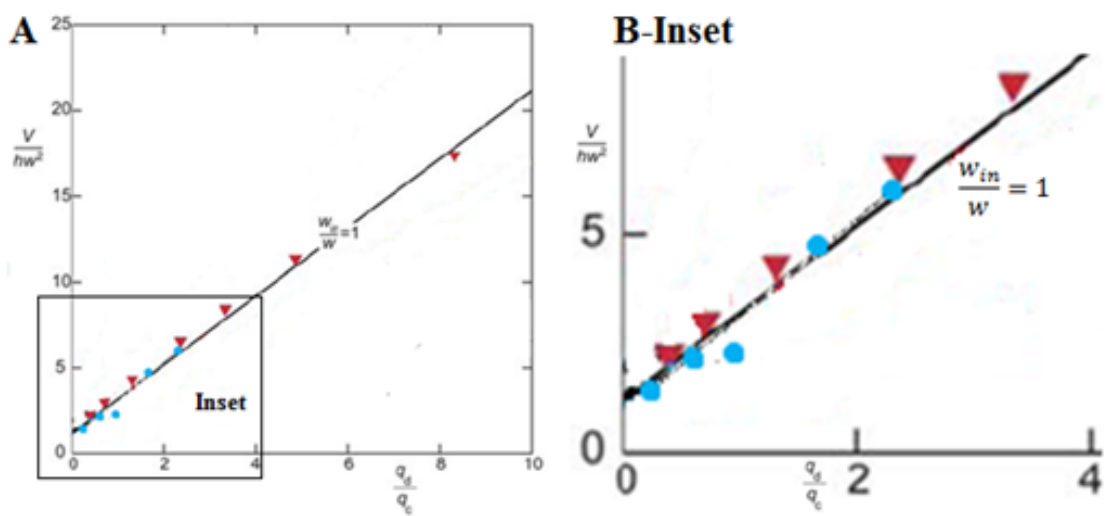

Figure 20: A-Image from the study performed by van Steijn, et al. The computationaldata points from my research are representedby the circles whichoverlay the experimental data points, triangles, provided by VanSteijn's study. The dimensionless volume is represented by

$V /\left(h w^{2}\right)$ on the vertical axis, and the ratio of the flow rates is represented by $q_{d} / q_{d}$ on the horizontal axis.B-Inset from Figure 20A.(reprinted with permission from Van Steijn, et al., 2010) 
In Figure 20, the triangles represent data provided by van Steijn. The circle represents data points from simulations performed on the cluster at San Jose State University. A favorable comparison between the two data sets validates the accuracy of the T-junction channel.In regards to the fluidic properties, all the values previously mentioned in Table III hold true except for the values of the flow rates, as they were adjusted to create each individual point.

\subsection{Merging Chamber}

After validating the accuracy of the T-junction, the merging chamber with pillars was then constructed and fused to the T-junction. Droplet merging was the second major focus of this project. Below in Figure 21, is an image of the pillar induced merging chamber.

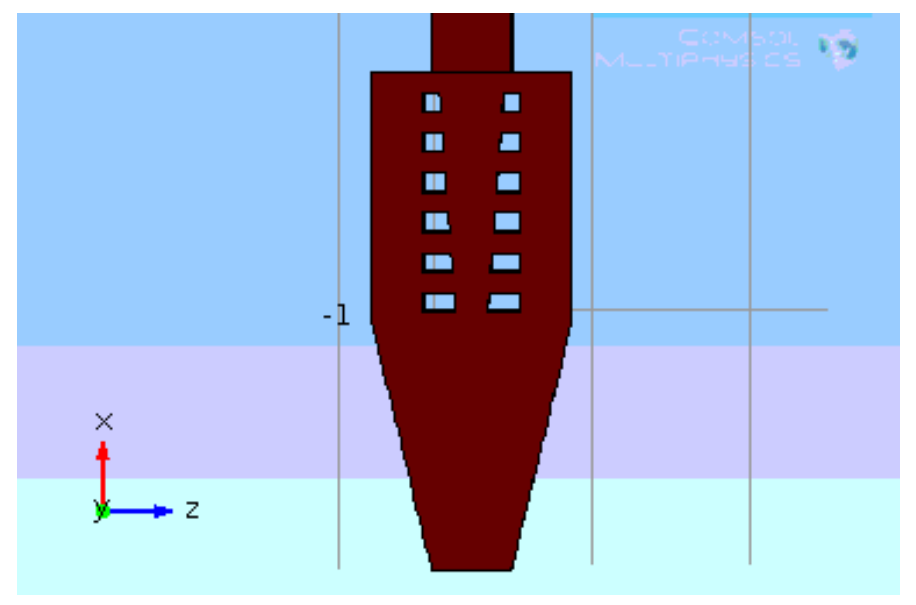

Figure 21: Image from COMSOL Multiphysics ${ }^{\circledR}$ of a pillar induced merging chamber. Droplets will enter the chamber through the small channel at the top of the figure. After leaving the channel, the droplets will then flow into the chamber of pillar arrays and reduce speed as the pillars get larger. The increasing size of the pillars causes flow of the droplets to slow even more. The slowing of droplets will result in droplet merging, and the fused droplets will leave the chamber via the channel at the bottom of the image. 
Droplet fusion was the most complex and computational intense region of this study. A majority of the simulations had droplets slowing, but the actual merging of the droplets was challenging. One simulation did result in the successful merging of droplets. However, this file was unintentionally cancelled early due to a power failure, but the file was partially recovered.

It is relevant to note that it took two weeks of continuous computation time on the cluster to complete approximately a quarter of the entire simulation. An extremely fine mesh was required for this simulation resulting in a more computationally time intensive study. Another major contributing factor to the increasing simulation time is the age of the technology. COMSOL Multiphysics ${ }^{\circledR}$ releases an updated version approximately everysix months to one year. The latest edition is an improved version, meaning more complex simulations can be constructed. The updated versions are designed for newer more robust systems. The cluster utilized for these simulations is an "older" system in terms of technology, meaning that solution times will be increased due to more partial differential equations required and the lack of processing power to solve the multitude of equations.

One major reason for doing computational research is to increase productivity by removing trial and error aspect of the design and fabrication process. However, two weeks to perform one quarter of a computation is not efficient enough to be a viable option for the design aspect. Although, the current system that is being used may not be useful for the more complex systems, the simulation itself does provide valuable physical intuition and visual understanding of the fluid phenomena. 
Images of droplets entering the expansion chamber can be seen in Figure 22. In Figure $22 \mathrm{H}$, the droplet within the pillars appears to be much smaller than the droplet entering the expansion chamber. Initially, this was thought to be a result of the droplets elongating as they squeeze through the pillars. The pillars increase in size as the droplets flow deeper into the merging chamber. Between Figure 22C and Figure22D, the droplet is elongating as it squeezes into the channel.

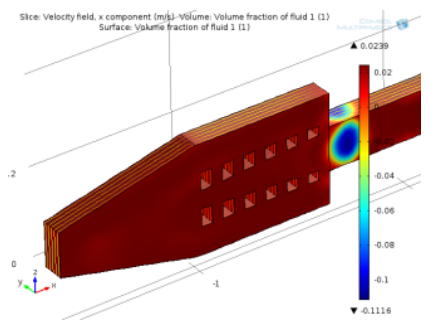

A- $-0.075 \mathrm{~s}$

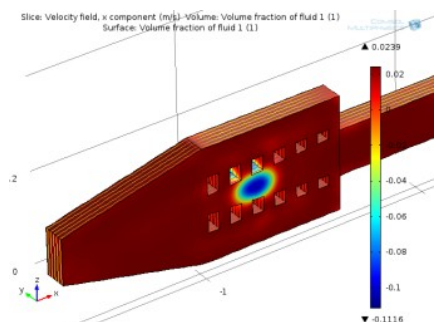

D-0.09 s

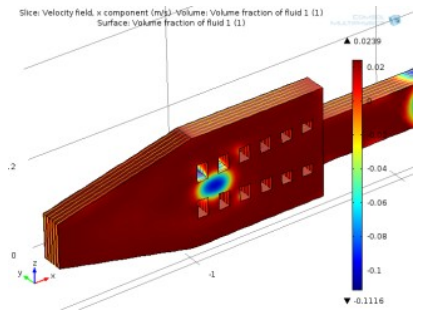

G-0.105 s

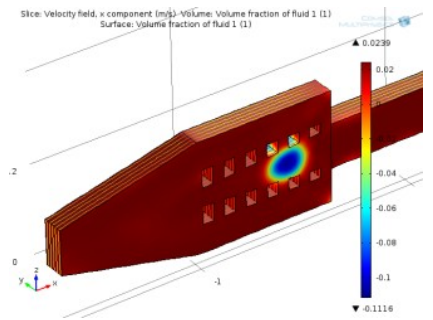

B- $0.08 \mathrm{~s}$

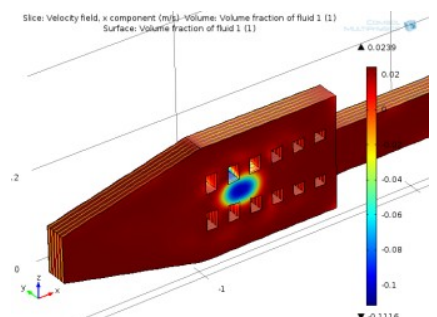

E-0.095 s

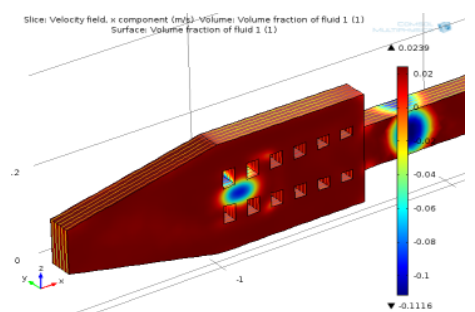

$\mathrm{H}-0.11 \mathrm{~s}$

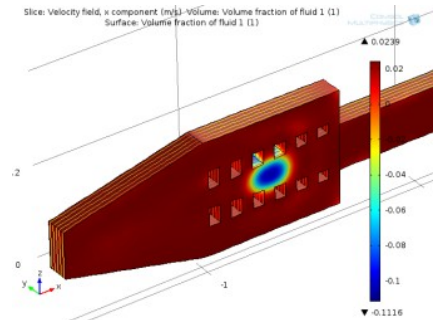

C-0.085 s

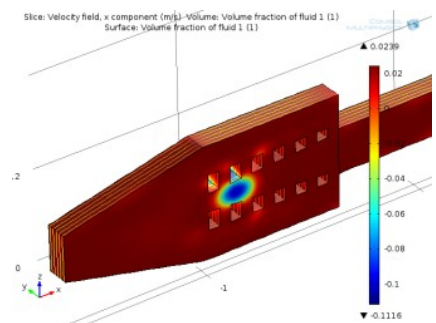

F-0.1 s

Figure 22: Images from COMSOL Multiphysics ${ }^{\circledR}$ of droplets entering the merging chamber. Each image shows the time elapsing by .005 seconds. 
When analyzing images D, E, F, G, and $\mathrm{H}$ from Figure 22 the droplet is slowly moving and simultaneously shrinking. During the simulation, the volume was not conserved. For fluid dynamics modules COMSOL Multiphysics ${ }^{\circledR}$ does not inherently conserve volume, but rather it conserves energy. Energy conservation is vital in solid mechanics, but is not as relevant as volume when performing fluid simulations.

The user had incorrectly assumed that volume was being conserved during the simulation. The model directions provided by COMSOL Multiphysics ${ }^{\circledR}$ discussed Newton's law, which is the initial step in fluid mechanics analyses. This was an oversight the simulator made when designing the T-junction and merging chamber. Even though this error was made, at the time this simulation was completed, there was not an option to conserve volume. The newer versions of COMSOL Multiphysics ${ }^{\circledR}$ are able to conserve volume, but it requires much more computational power than the nonconservative form. Therefore, resulting in an even longer study time, thus making any further studies a less efficient and viable option. 


\section{Chapter 6: Conclusions}

In this study, computational fluid dynamics were successfully used to optimize and predict outcomes for droplet formation through a variety of generating regimes and droplet fusion in merging chambers. The nature of COMSOL Multiphysics ${ }^{\circledR}$ is versatile and allows two and three-dimensional analysis, thereby providing more computationally time-effective analysis.

The results from this nozzle study will be utilized by the deMello group. From these results, the group will forego designing a nozzle with a width of $23 \mu \mathrm{m}$ and focus on the $45 \mu \mathrm{m}$ and $100 \mu \mathrm{m}$ nozzle widths. The two most robust post nozzle geometries were the 90 degree and the gradual. These two post nozzle geometries were able to yield droplets when combined with a nozzle width of $23 \mu \mathrm{m}$, the least successful nozzle width. With this knowledge, the deMello group will be able to improve their designs and test the simulated designs that yielded positive results.

In terms of simulation, the next step with the nozzles would be to use the same geometries but to increase the oil and water flow rates, as some biological and chemical systems require fluid to flow at a higher Reynolds number. If the flow rate can be increased and stable droplets formed, then this would open a new avenue for microanalysis to be performed in chemical and biological systems.

The three-dimensional droplet generation and fusing experiments were successful. The three-dimensional T-junction generated droplets of consistent volumes that 
compared favorable with the data provided by van Steijn. Although, the droplet fusion did not conserve volume, the droplets did successfully fuse within the merging chamber. 


\section{BIBLIOGRAPHY}

1. van Steijn, V.; Kleijn, C.; Kreutzer, M. Predictive model for the size of bubbles and droplets created in microfluidic T-junctions. Lab Chip 2010, 10, pp 2513-2518.

2. Lee, S. J.; Sundararajan, N. Microfabrication for Microfluidics. Artech House: Norwood, MA, 2010; pp 2.

3. Stone, B.M; deMello, A.J. Life, the universe and microfluidics.Lab Chip[Online] 2002, 2, pp 58N-64N.

4. Basu, A. National Nanotechnology Infrastructure Network. http://lnf.umich.edu/nninat-michigan/multiphase-cfd/ (accessed January 29th, 2013).

5. Frenz, L; Harrak, A.E; Pauly, M; Begin-Colin, S; Griffiths, A.D; Baret, J.C. Dropletbased microreactors for the synthesis of magnetic iron oxide nanoparticles.Angew.

Chem.2008, 47, pp 6817

6. Cho,S; Kang, D.K; Sim, S; Geier, F; Kim, J.Y; Niu, X; Edel, J.B; Chang, S.I; Wootton, R.C.R; Elvira, K.S; deMello, A.J. Droplet-Based Microfluidic Platform for High-Throughput, Multi-Parameter Screening of Photosensitizer Activity.Ana. Chem. 2013 85, pp 8866-8872.

7. Mazutis, L.; Griffiths. A. Preparation of monodisperse emulsions by hydrodynamic size fractionation. Applied Physics Letters2009, 95, pp 204103.

8. Tan, Y.C; Ho, Y.L; Lee, A.P. Microfluidic sorting of droplets by size. Microfluidics and Nanofluidics 2008, 4, pp 343-348.

9. Xu, B; Nguyen, N.T; Wong, T.N. Droplet Coalescence in Microfluidic Systems. Micro and Nanosystems[Online] 2011, 3, pp 131-136. 
10. Niu, X; deMello, A. Building droplet-based microfluidic systems for biological analysis. Biochemical Society Transactions 2012, 40, pp 615-623.

11. Surenjav, E; Herminghaus, S; Priest, C; Seeman, R. Discrete microfluidics: Reorganizing droplet arrays at a bend. Applied Physics Letters 2009, 95, pp 154104.

12. Barker, N. Slow is Faster. http://blog.nialbarker.com/252/slow_is_faster (accessed October 24, 2013.

13. Day, M.A. The no-slip condition of fluid dynamics.Erkenntnis1990, 33, pp 285-296.

14. Skoog, D.A; Holler, F.J; Nieman, T.A. Principles of Instrumental Analysis, 5th ed. Saunders College Publishing: Philadelphia, 1998.

15. ComsolMultiphysics. Sales. https://technic.com.au/images/company/products.jpg (accessed on October 23, 2013)

16. ComsolMultiphysics. Level Set method for two-phase flow, how does it compare with the Volume of Fluid (VOF) method? http://www.comsol.com/support/knowledgebase/1025/ (accessed October 23, 2013).

17. COMSOL Multiphysics. Droplet Breakup in a T-junction. http://www.comsol.com/model/download/176241/models.mfl.droplet_breakup.pdf (accessed on November 4, 2013).

18. Chen, J.M; Kuo, M.C; Liu,C.P. Control of Droplet Generation in Flow-Focusing Microfluidic Device with a Converging-Diverging Nozzle-Shaped Section. Japanese Journal of Applied Physics 2011,50, pp 107301-1-107301-7.

19. Abate, A.R; Mary, P; van Steijn, V; Weitz, D.A. Experimental validation of plugging during drop formation in a T-junction. Lab Chip2012, 12, pp1516-21. 